\title{
Estimating TBM Specific Energy by Employing the Rock Mass Strain Energy, A Case Study: Karaj - Tehran Water Conveyance Tunnel located in Iran
}

Majid Mirahmadi ( $\sim$ m_mirahmadi@pnu.ac.ir)

Payame Noor University https://orcid.org/0000-0002-0574-5752

\section{Research Article}

Keywords:

Posted Date: May 27th, 2021

DOl: https://doi.org/10.21203/rs.3.rs-462135/v1

License: (c) (i) This work is licensed under a Creative Commons Attribution 4.0 International License.

Read Full License 
Estimating TBM specific energy by employing the rock mass strain energy, a Case Study: Karaj - Tehran Water Conveyance Tunnel located in Iran

\begin{abstract}
Recently energy costs are increasing so it is critical to master the challenge of energy efficiency. Energy consumption for drilling in tunnel Boring Machines (TBMs) is mainly determined by the specific energy. Specific energy is the amount of energy needed to excavate a unit volume of rock mass and is considered one of the important parameters used for performance prediction of TBMs. This study tries to apply the strain energy of a rock mass to develop a new method for foretelling specific energy for TBM. The area under complete stress-strain curve is known as strain energy which is pertinent to the rock mass behavior, pre and post failure properties, peak strain and post peak strain. In this study statistical analysis performed through collected actual data from Karaj Tehran Water Conveyance Tunnel revealed a new relationship between the specific energy used by TBM (SE) and the strain energy. For more detailed study the rock mass classification is performed with respect to the geological strength index and all geological units are then classified in three classes and the specific energy of TBM is predicted based on the strain energy of rock mass for each three classes. The results reveals that two parameters of the specific energy and the strain energy are in a direct relation whose correlation is increased with considering the rock mass classification based on the post peak behavior of rock mass.
\end{abstract}

Keywords: specific energy, post failure manner, torque, thrust, strain energy

\title{
- Introduction
}


The units of energy needed to digging out a unit volume of a rock mass is called the specific energy of excavation. For the first time, Teale (1965) in the petroleum industry introduced the idea of the SE as a framework for evaluating the effectiveness of the drilling processes and excavating in rock masses. In real time, this parameter can be calculated from the data which show the performance of a TBM or a drilling machine. Boyd (1986) computed penetration rate with respect to the specific energy of a rock mass [1]. What is more interesting is that this parameter is proved to be correlated with the rock mass mechanical properties [2]. Researchers like Murhead and Glossop (1968), Hustrulid (1970) indicated that SE has also an acceptable correlation with uniaxial compressive strength (UCS). Altindag (2003) showed a meaningful relationship, with strong correlation coefficients, between the amount of the specific energy and the brittleness of the rock mass [3]. Bieniawski et al. (2007) found correlation between Rock Mass Excavability (RME) and SE. Acaroglu et al. (2008) exerted fuzzy logic method to create a model which can forecast specific energy requirement of constant cross-section disc cutters in the process of cutting rocks. Atici \& Ersoy (2009) evaluated the impact of brittleness and destruction energy on SE. Zhang et al (2011) invented a recognition model of the specific energy by presenting the mechanical analysis of the shield digging out process into the nonlinear multiple regression of the on-site data. Wang et al (2012) amended disc cutter radius and proposed new SE equations accordingly.

It is obvious that in the process of excavating a given volume of rock, a definite theoretically minimum quantity of energy is necessary and its exact amount will completely depend on the nature of the rock mass. The actual mechanical processes probably approximate to this theoretical minimum. The existing difference between factual and theoretical prerequisites would be a measure of work. This would be evanesced in various phases like in breaking the excavated 
rock into pieces smaller than required, in friction between tools and rock (conceivably amounting to the very thing on a microscopic scale), or in mechanical losses quite outside the rock system [4]. The concept of specific energy and its related applications will be illustrated in the next section.

\section{- Concept of specific energy}

The consumed amount of energy to accomplish the excavation of unit volume of rock mass is called the specific energy [5] that is practically considered as a profitable parameter with capability to assess how much energy is needed for a specific cutting process. The value of SE equals to the forces imposed on disc cutters whose estimation can be done by applying TBM operation parameters [6]. SE comprises two components both of which respectively arise from the rolling and the thrust forces of the disc cutter. Fig. 1 indicates a schematic model of working TBM as well as forces. During excavating, the machine is moving by the thrust $(F)$ which mostly consumes the energy to continuously move the machine forward and the torque $(T)$ which consumes the rest of energy to maintain the cutter forward in the continuously rotating position to cut the rock mass. The micro fracture is actually produced by the required thrust in rock mass. That is, there is a relationship between the thrust force and the pre failure section of complete stress-strain curve of rock mass. The value of torque force, on the other hand, is related to rock mass the post failure manner as it is used to propagate both micro and macro fractures. 

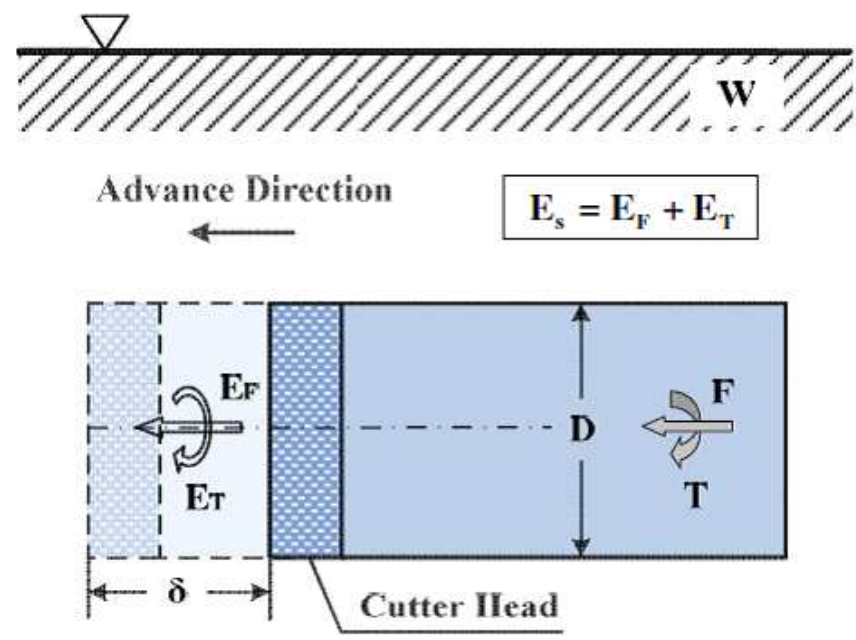

Fig. 1 Schematic representation for the working process of a shield machine [5]

Teale (1965) suggested the specific energy as the following expression [4]:

$\mathrm{SE}=\left(\frac{\mathrm{F}}{\mathrm{A}}\right)+\left(\frac{2 \mathrm{~K}}{\mathrm{~A}}\right)\left(\frac{\mathrm{NT}}{\mathrm{u}}\right)$

Where: SE equals to specific energy of excavation $\left(\frac{M J}{m^{g}}\right), F$ equals to total cutter head thrust (KN), A equals to excavated face area $\left(\mathrm{m}^{2}\right), \mathrm{N}$ equals to cutter head rotation speed (rps), $\mathrm{T}$ equals to applied torque $(\mathrm{kNm})$, and $\mathrm{u}$ equals to average rate of advance $(\mathrm{m} / \mathrm{s})$.

Equation (1) includes two terms: the first stands for the specific energy consumed by the cutter head thrust in static loading position and the second stands for the specific energy incurred by rotating cutter head in rotation position.

As stated by Acaroglu et al (2008), SE signifies a function of rolling force and the cutting profile area (as shown in Eq. 2) [2]. 
$\mathrm{SE}=\frac{\mathrm{F}_{\mathrm{K}} \cdot \mathrm{R} \cdot \mathrm{t}}{\mathrm{V}}=\frac{\mathrm{F}_{\mathrm{K}}}{\mathrm{A}}$

where SE is the specific energy $(\mathrm{kW} \mathrm{h} / \mathrm{m} 3) ; \mathrm{F}_{\mathrm{R}}$ is the rolling force $(\mathrm{kN}) ; \mathrm{R}$ is the velocity of cutting $(\mathrm{m} / \mathrm{s})$; $\mathrm{t}$ is the cutting time (s); V is the volume of the excavated rock (m3); $\mathrm{A}$ is the profile area of the cutting which is a function of the cutting penetration and spacing between cuts.

Fig. 1 displays cutting forces acting as the disc cutter performance parameters as well. Eq. (3) uses the SE value attained from Eq. (1) to the estimate instantaneous penetration rate (IPR).

$\operatorname{IPR}=\frac{P \cdot K}{\operatorname{SE} \cdot A_{\mathrm{E}}}$

Where IPR signifies the instantaneous penetration rate $\left(\frac{m}{h}\right) ; \mathrm{P}$ signifies the power of cutter head of the machine $(\mathrm{kW})$; SE signifies the specific energy $\left(\frac{K W h}{m^{\mathrm{g}}}\right) ; \mathrm{k}$ signifies the mechanical efficiency factor; $\mathrm{A}_{\mathrm{t}}$ signifies the tunnel area $\left(\mathrm{m}^{2}\right)$.

Moreover, specific energy can be applied to both estimate and compare cutting efficiency (production rates) of mechanized systems. It plays a significant role in defining their optimum cutting geometries (optimum ratio of depth of cut to line spacing) for a given rock sample [7]. Specific energy is assessed as [8]:

$S E=\frac{F C}{Q}$

Where $S E$ indicates specific energy $\left(\frac{M J}{m^{\mathrm{g}}}\right), F C$ indicates cutting force acting on the tool $(\mathrm{kN})$, and $Q$ indicates yield or rock volume cut in unit cutting length $\left(\frac{\mathrm{m}^{\mathrm{a}}}{\mathrm{km}}\right)$.

SE value in theoretical terms means the area which is subjected to the complete stress- strain curve in an unconfined compression test (see Fig. 2 [9]). Brittle and ductile rock masses show 
completely various failure behavior; that is, they rupture without any noticeable deformation in a brittle failure mode but distort elastically until they yield in a plastic failure mode. Plastic deformation then takes place until they break down (Fig. 2). The envelope curve integral physically equates to the volume related energy (or work). Since this property is a necessity for drilling the rock mass, it is called specific energy for drilling. Including the post-failure section, the process of shape adapting which stems in stress-strain as well as specific destruction energy (SE) will be calculated. Inasmuch as the deformation modulus indicates the gradient (derivation) of linear section, it is derived from the next equation [10]:

$\mathrm{SE}=\int \sigma_{\mathrm{r}} \mathrm{d} \varepsilon$

Where equates the specific energy $\left(\mathrm{KJ} / \mathrm{m}^{3}\right)$; equates the stress $(\mathrm{MPa})$; $\varepsilon$ equates the strain.

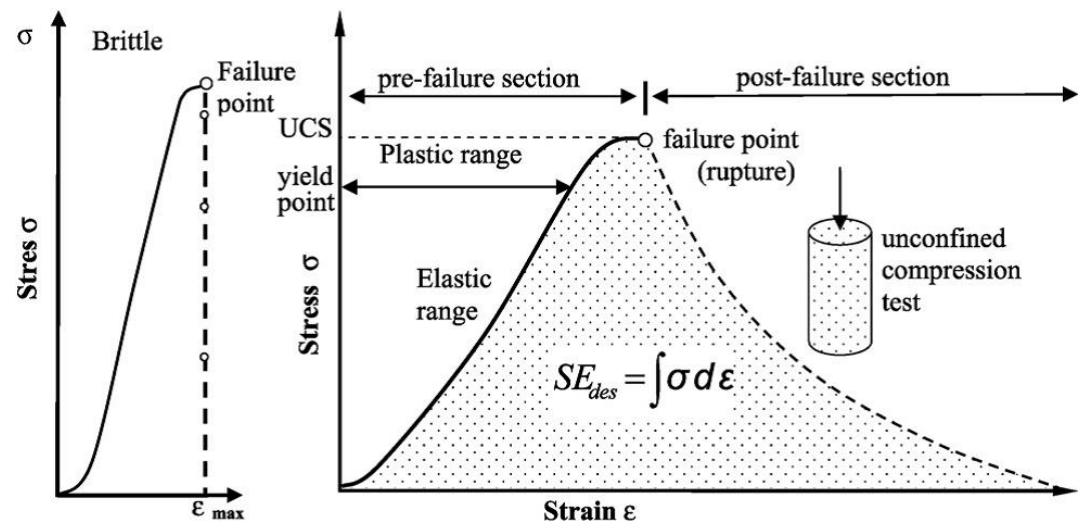

Fig. 2 Assessing the destruction specific energy $\left(\mathrm{SE}_{\mathrm{des}}\right)$ out of the stress-strain curve of a rock sample subjected to unconfined compression test [10].

The strain energy will be discussed in the following section.

\section{- $\quad$ Strain Energy Theory}


The present research used Dehkordi's proposal as a basis for evaluating the strain energy of rock mass [11]. Stain energy refers to the area under stress-strain curve and its estimation, as illustrated in the following sections, depends on the rock mass behavior, pre and post failure properties, peak strain and post peak strain.

\section{- Rock Mass Behavior Modes}

The following guidelines were suggested by Hoek and Brown (1997) for estimating various types of post failure manner shown by rock mass regarding their quality. The basis of these guideline is rock types [12]:

- For hard rock with excellent quality $(70<\mathrm{GSI}<90)$, the rock mass behaves in elastic brittle manner.

- For averagely joint rock $(50<\mathrm{GSI}<65)$, a failure of joint system occurs because of moderate stress levels and the rock mass, as a result, behaves in serious manner.

- For heavily jointed rock $(40<\mathrm{GSI}<50)$, the rock mass behaves in strain softening manner, and

- For very fragile rock (GSI<30), the rock mass behaves in an elastic completely plastic manner without any stretch (as shown in Fig. 3). 


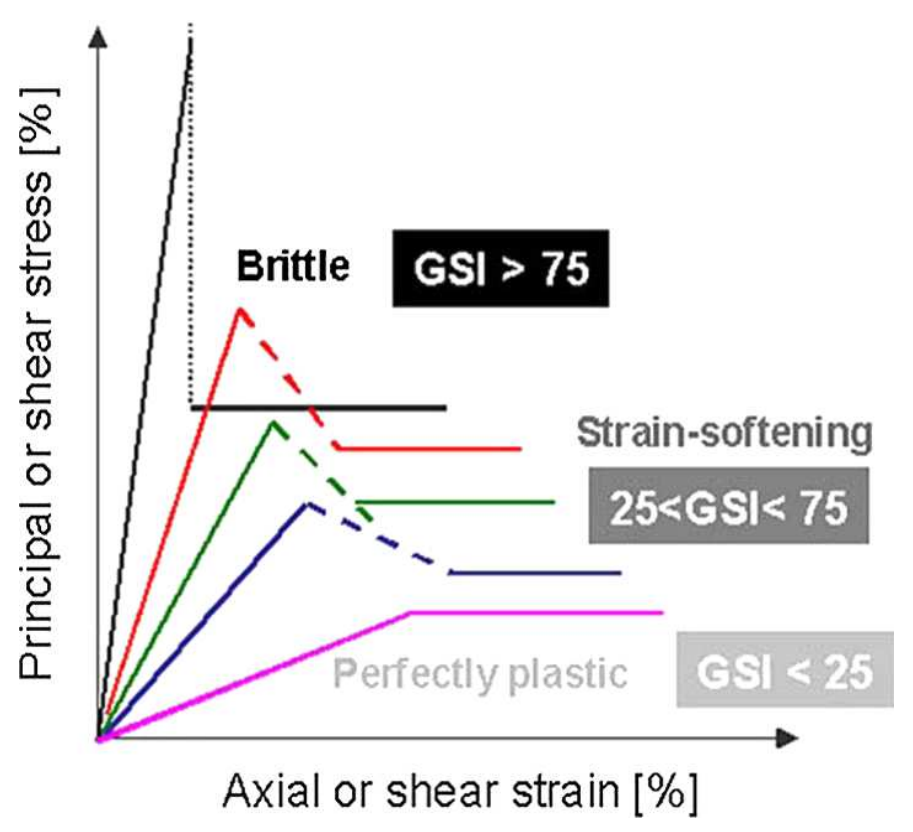

Fig. 3 Various post-failure behavior styles shown by assorted rock masses having different geological strength indices (GSI) [13]

These concepts will be clearly shown in Fig. 3. Brittle and elastic perfectly plastic behaviors are numerated as the special instances of the strain softening behavior in that they can all be purely accommodated [14].

- Hoek-Brown failure as a criterion for estimating the maximum and minimum principal stresses

As it was mentioned previously, all post failure behaviors can be accommodated by the strain softening behavior which is identified by a gradual transition from a peak failure criterion to a residual one controlled by the softening parameter $\eta[15]$. In this model, where the softening parameter equates null, an elastic state takes place, where $0<\eta<\eta^{*}$, the softening state happens, and where $\eta>\eta *$, the residual state occurs. $\eta^{*}$ refers to the softening parameter value which 
has a control over the transition between the stages of softening and residual (See Fig. 4). The strain-softening model comprises three models of perfectly fragile or elastic-fragile-plastic and completely plastic. The necessary information to classify a strain-softening rock mass follows as: (1) Peak and residual failure criteria, (2) elastic parameters (Young's modulus and Poisson's ratio), and (3) post-failure deformability parameters. Joints, micro-cracks, and groundwater are three factors that have a reduction effect on the strength of rock mass. In respect to the HoekBrown failure criterion, the scaling parameter of GSI can estimate the descended strength of rock mass and as an empirically dimensionless number can change over a scale with minimum of 10 and maximum of 100 . Therefore, the GSI value near to 10 indicates very low quality of rock masses and the GSI value near to 100 shows the excellent quality of rock masses [12, 17-19].

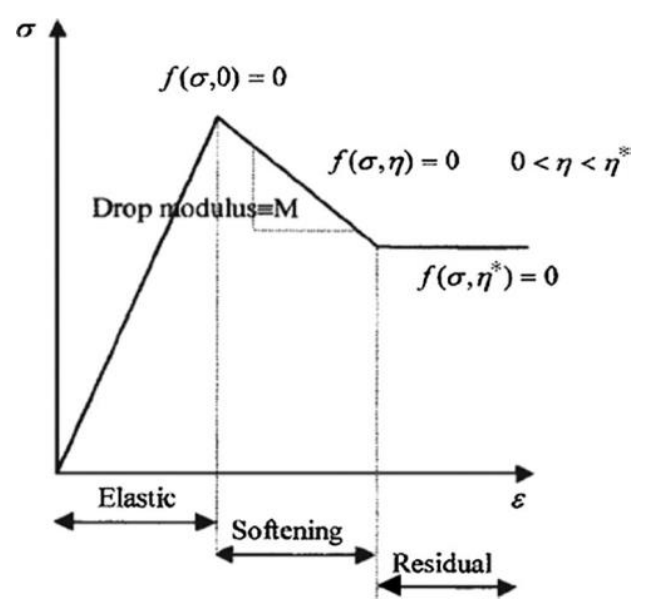

Fig. 4 Stress-strain curve with regard to an unconfined test performed on a specimen of strainsoftening material [13]

After introducing the GSI scale factor, the Hoek-Brown criterion for the rock mass can be represented as follow [20]: 
$\sigma_{1}=\sigma_{\mathrm{a}}+\sigma_{\mathrm{ci}}\left(\mathrm{m}_{\mathrm{b}}, \frac{\sigma_{\mathrm{z}}}{\sigma_{\mathrm{ci}}}+\mathrm{s}\right)^{\mathrm{a}}$

(6)

The parameters that have an effect on the parameter $m_{\mathbb{E}}$ in Eq. (6) comprise the intact rock parameter, $\mathrm{m}_{\mathrm{i}}$, the value of GSI, and the disturbance factor $\mathrm{D}$, as described by the next equation $[18,21]:$

$\mathrm{m}_{\mathrm{b}}=\mathrm{m}_{\mathrm{i}}, \exp \left(\frac{\mathrm{CSI}-100}{28-14 \mathrm{D}}\right)$

The factor D is influenced by the degree of disturbance the rock mass has experienced because of blast damage and stress relaxation. This factor varies from 0 to 0.8 for respectively undisturbed in situ and very disturbed rock masses in tunnels $[12,18,21]$. The GSI value and factor D have an empirical effect on the parameter s as the following $[12,18,21]$ :

$S=\exp \left(\frac{6 S I-100}{9-3 D}\right)$

Besides the parameter s, the parameter a is also empirically dependent on GSI value, as follows [18]:

$a=\frac{1}{2}+\frac{1}{6}\left(e^{\frac{-651}{15}}-e^{\frac{-20}{3}}\right)$ 
Since the confinement stress has an influence on the behavior type of rock mass, achieving the correct value of $\sigma_{1}$ to be used in Eq. (6) is significant. To be more specific, when the amount of confinement stress escalates, the rock mass shows increasingly pliable and ultimately, ideal plastic manner and when this amount de-escalates, the post peak behavior of rock mass becomes more brittle [14]. The confinement stress is evaluated by Eq. (10) [18]:

$\frac{\sigma_{3}}{\sigma_{\mathrm{cm}}}=0.47\left(\frac{\sigma_{\mathrm{cm}}}{{ }_{\mathrm{mH}}}\right)^{-0.94}$

Where $\sigma_{\mathrm{cm}}$ is the rock mass strength, specified by Eq. (11), $Y$ is the unit weight of the rock mass, and $\mathrm{H}$ is the depth of the tunnel below surface. Where the horizontal stress precedes the vertical one, the horizontal stress should replace $\left.\mathbb{V}^{1} 18\right]$.

$\sigma_{\mathrm{cm}}=\frac{2 \operatorname{coc} \cos \phi}{1-\sin \phi}$

Where $\mathrm{C}$ equates the cohesion of rock mass and $\Phi$ equates the friction angle of rock mass.

This study employed the Hoek and Brown proposal to assess Peak properties of rock masses. The inclination for the softening stage or drop modulus is designated by M. If the drop modulus tends to infinity, perfectly brittle behavior is observed; otherwise, if it tends to zero, perfectly plastic behavior is achieved [13]. The confinement stress is one of the most significant factors influencing the drop modulus; that is, if this criterion raises, the rock mass will show increasingly fragile and eventually ideally plastic manner [22] whereas it reduces, drop modulus approximates to zero and the rock mass will indicate fragile manner and the drop modulus approaches infinite. Seeber Carranza-Torres and Fairhurst (2000) concluded that where the 
confinement pressure $\sigma_{3}$ equates or precedes one-fifth of the axial stress at failure, completely plastic behavior may occur, without any strain softening post failure (Fig. 5) [23]. To attain the kind of relation between the confinement pressure and the uniaxial compressive strength rc of the undamaged rock, Hoek and brown failure criterion and Seeber's condition should be taken in to account. This relation can be approximated by:

$\sigma_{3, \text { crit }} \geq \frac{\sigma_{c, m_{b}}}{16}$

Where $m_{b}$, is the product of parameter $m$ influenced by the lithology, with a reduction factor influenced by the degree of fracturing of the rock.

(a)

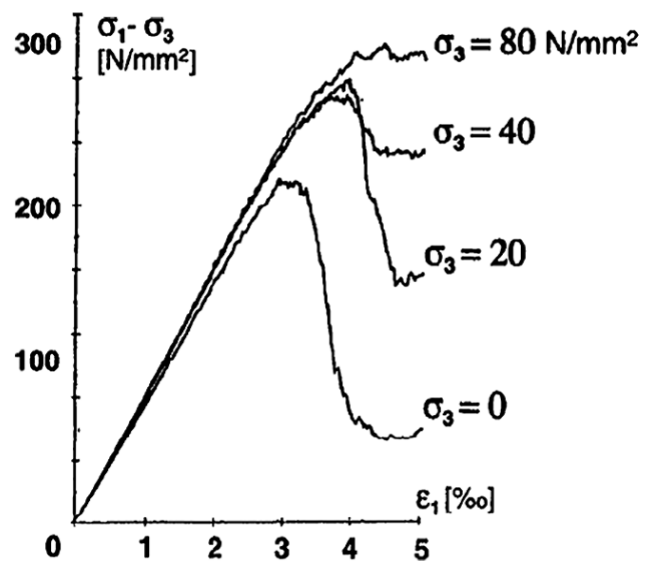

(b)

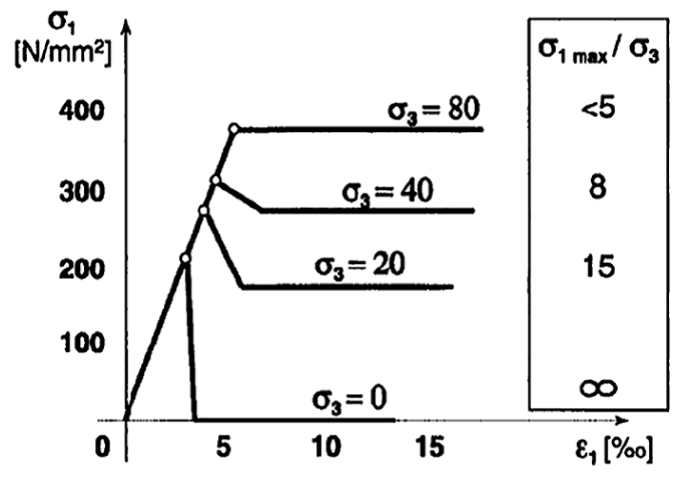

Fig. 5 The post-failure behavior of granite samples determined by the confinement pressure. (a) Outcomes of a numerical simulation of the 3-axial tests.( b) Schematic behavior [24].

- Assessing approaches of pre and post failure deformability 
As a highly influential parameter in mechanical behavior of rock mass, the deformation modulus can be estimated by manifold methods such as back analysis employing numerical methods, in situ tests, and empirical equations, which designate rock mass classifications as the basis. Although in situ tests are the foremost method employed for this job, they are expensive and often very arduous. Therefore, rock engineers and engineering geologists tend to replace other methods. In this regard, empirical method can easily be used to estimate and acquire $\mathrm{E}_{\mathrm{rm}}$.

Empirical approaches is used as well for attaining the pre failure deformability. Hoek and Diederichs approach can be used to acquire the deformation modulus, $\mathrm{E}_{\mathrm{rm}}$, because it includes more other factors exist which have a greater effect on deformability like the elastic modulus of intact rock, $\mathrm{E}_{\mathrm{i}}$, disturbance factor, D, and GSI [25]: 5475

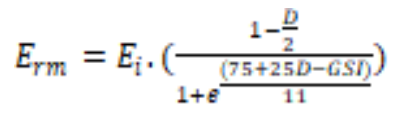

The rock behavior is not usually actuated by Poission's ratio, $v$, to a significant degree. Thereupon, standard values in the range of $0.25-0.35$ seems to be valid for any approach [11]. There are two factors on which post-failure behavior of rock masses regarding their deformability immensely relies; namely, rock mass quality and confinement stress. Taking in to account the stated observations, the suggested values by Alejano et al. (2009) were applied as an assessment for drop modulus of rock mass in keeping with both the peak rock mass quality specified by GSI peak and the confinement stress level referred to in relation to the rock mass compressive strength obtained by $\sqrt{\mathrm{S}^{\mathrm{pealk}}}{ }_{{ }^{\circ} \sigma_{\mathrm{EI}}}$. Accordingly, the acquired values suppose a constant trend from fragile to pure ductile behavior in respectively rock masses in excellent condition experienced unconfined situation and rock masses in terrible condition subjected to enormously 
confinement stresses. The drop modulus values, based on Alenjian's equations, depend on the deformation's modulus, $\mathrm{E}_{\mathrm{rm},}$ [13]:

$\mathrm{M}=-\omega \cdot \mathrm{E}_{\mathrm{rm}}$

The ratio value which is dependent on the GSI ${ }^{\text {peak }}$ and confinement-stress level can be obtained by Eqs. 15, 16:

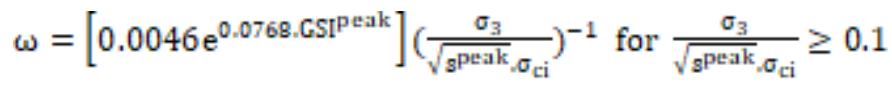

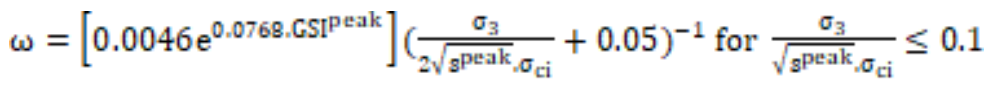

When the confinement stresses are disregarded in calculation, the drop modulus can be evaluated by Eq. (17) [13]:

$\mathrm{M}=\frac{\mathrm{E}_{\mathrm{rm}}}{0.08 \mathrm{GSI}-7} \quad$ For $\quad 25<G S I<75$

The drop modulus can also be estimated by a more complicated method including the effect of $\sigma_{\text {เี่ }},[13]:$

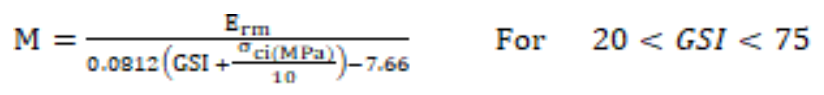


If more complicated strain softening models with confinement stress influenced by drop modulus are preferred for calculating the drop modulus, the succeeding equation should be considered as the first approach [13]:

$\mathrm{M}=\frac{1000 \cdot \mathrm{B}}{6 \text { GS1. } \sigma_{3}+75.6 S 1-225 \sigma_{3}-5875} \quad$ For $\quad 5<G S I<75$

The most intricate equation to assess the modulus of drop is proposed in the following:

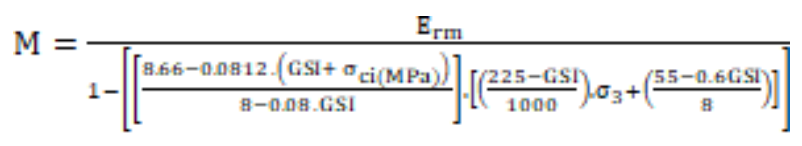

Equation 20, which is used for GSI ranging from 20 to 75, and more effective factors such as GSI, confinement stress, unixial strength of intact rock, etc. are applied in this equation [13]. This equation employs equation 20, applied for GSI ranging from 20 to 75, plus more efficient parameters like GSI, confinement stress, uniaxial strength of intact rock, etc. [13]. The entire equations referred to above had been applied to estimate the drop modulus in this study.

\section{- Estimation of axial strain in peak strength}

Sakurai (1997) and Sakurai and Takeuchi (1983) suggested a method whereby the stability of underground construction can be investigated. This method which was based on the results acquired from the uniaxial compression tests to ascertain the critical strain is used to the convergence method coming out of different tunnel inquires. Considering the relationship 
between uniaxial compressive strength and critical strain, Sakurai and his colleagues introduced the following equations for the modulus of deformation. Equation 21 and 23 in the following respectively indicate the upper and lower limit of critical strain and equation 22 uses the logarithmic value of mean equations 21 and 23 , Where $\varepsilon_{\mathbb{e}}$ is the critical strain and $\mathbb{E}$ is the modulus of deformation $\left(\mathrm{kgf} \mathrm{cm}^{-2}\right)[\underline{26}, \underline{27}]$.

1. Risk alarm level I

$\log \varepsilon_{\mathrm{c}}=-0.25 \log \mathrm{E}-1.59$

2. Risk alarm level II

$\log \varepsilon_{\mathrm{c}}=-0.25 \log \mathrm{E}-1.22$

3. Risk alarm level III

$\log \varepsilon_{\mathrm{c}}=-0.25 \operatorname{LogE}-0.85$

According to Sakurai, what should be regarded as a base for designing tunnels in civil engineering is risk alarm level II. On the other hand, risk alarm level III which shows short-term stability was applied in this study to evaluate the axial strain in peak strength.

\section{- Estimating the strain energy}

Soleiman Dehkordi et al $(2011,2013)$ suggested a method, regarding the following equations, to evaluate the strain energy in two sections; namely, the supplied strain energy of pre-failure and the unconsumed strain energy of post failure. This evaluation was done by considering linear behaviors of pre and post failure (see Fig. 6). 


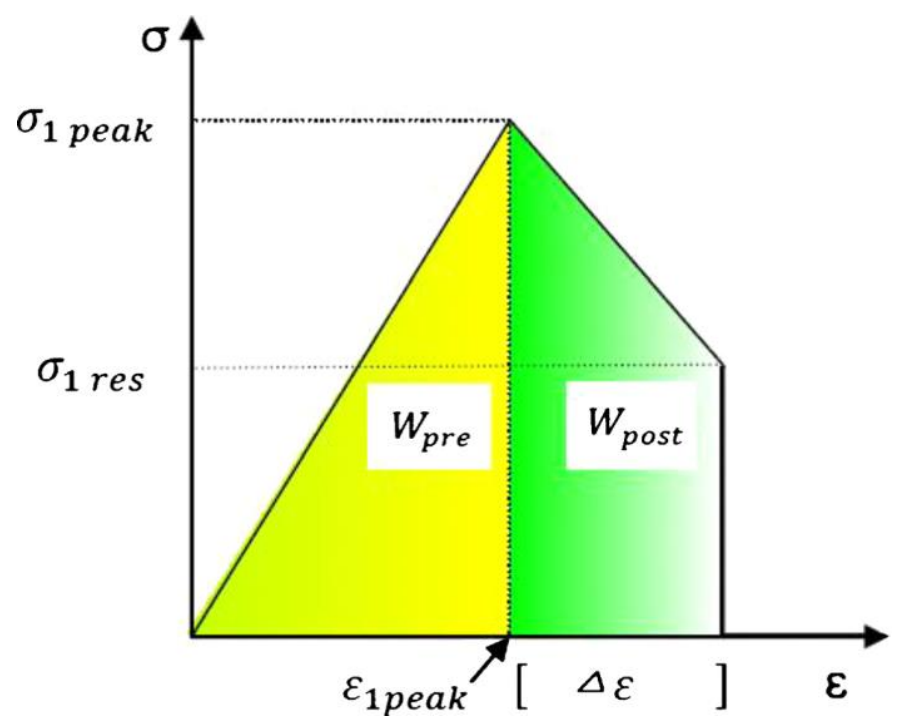

Fig. 6 Supplied and unconsumed strain energy in pre- and post-failure, respectively [28]

Eqs. 24 and 25 are therefore used to calculate the strain energy, W, in pre- and post-failure:

$W_{\text {pre }}=\frac{1}{2} \sigma_{1 \text { peak }}, \varepsilon_{1 \text { peak }}$

$W_{\text {post }}=\frac{1}{2}\left[\sigma_{1 \text { peak }}+\sigma_{1 \text { res }}\right] \cdot \Delta \varepsilon$

Where $w_{\text {pre }}$ and $w_{\text {post }}$ are stored and residual strain energy in pre- and post-failure, respectively; $\varepsilon_{1 \text { peak }}$ is the strain in peak point, and $\Delta \varepsilon$ shows the post peak strain (changing the strain from peak to residual strength), estimated according to the following equations:

$\mathrm{M}=\frac{\Delta \sigma}{\Delta \varepsilon}=\frac{\sigma_{1 \text { res }-\sigma_{1 \text { peak }}}}{\varepsilon_{1 \text { res }-\varepsilon_{1 \text { peak }}}}$ 
$\Delta \varepsilon=\frac{\sigma_{1 \text { res }}-\sigma_{1 \text { peak }}}{\mathrm{M}}$

The total strain energy will then be calculated.

$\mathbf{W}=\mathrm{W}_{\text {post }}+\mathrm{W}_{\text {pre }}$

Soleiman Dehkordi et al's proposal and the actual data of Karaj-Tehran Water Conveyance Tunnel of Iran were exerted in this paper to estimate the strain energy of rock mass.

\section{- Projects description and geology}

Karaj-Tehran Water Conveyance Tunnel (lot 2) as one of the components of a water management system in Iran has been excavated by employing double shield TBM Herrenknecht model S323. Table 2 presents technical characteristics of double shield TBM Herrenknecht model S323.

Table 2 Technical requirements of double shield TBM Herrenknecht model S323

\begin{tabular}{ll}
\hline Excavation machine type & Double Shield TBM \\
\hline Length of machine & $166 \mathrm{~m}$ \\
\hline Length of Shield & $10.6 \mathrm{~m}$ \\
\hline Weight of machine & 750 ton \\
\hline Weight of Shield & 170 ton \\
\hline Weight of cutter head & 45 ton \\
\hline
\end{tabular}




\begin{tabular}{ll}
\hline Number of disc cutters & 31 \\
\hline Average Spacing of disc cutters & $75 \mathrm{~mm}$ \\
\hline
\end{tabular}

This tunnel with its circular shape is located in the Chaloos road. It is exactly started from Amir Kabir Karaj dam and will continued to water softening (No: 6) of Tehran, about $35 \mathrm{~km}$ west of Tehran. This tunnel whose portal is exhibited in Fig. 9 is $4.66 \mathrm{~m}$ in diameter with a crosssectional area of $17.05 \mathrm{~m}^{2}$ and a length of $13.45 \mathrm{Km}$.

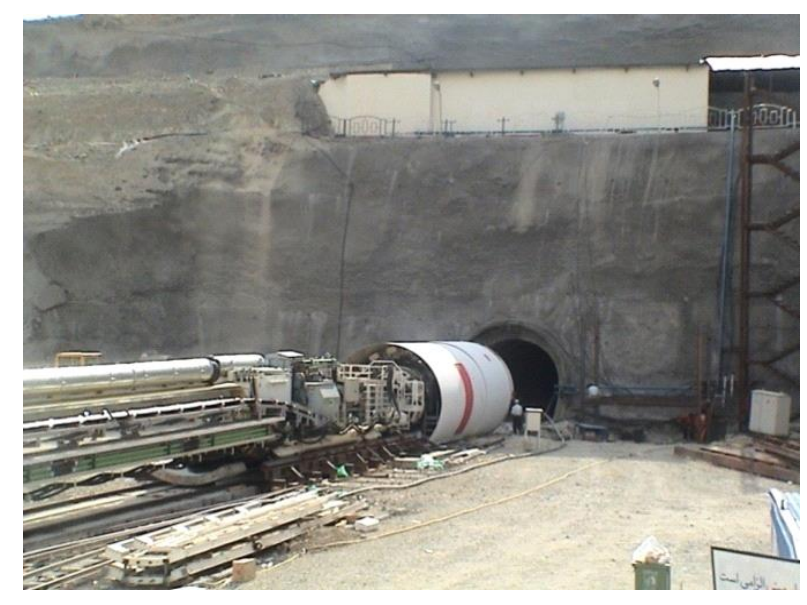

Fig. 9 The portal of Karaj-Tehran water conveyance tunnel

This tunnel consists of five types of rock masses including Siltstone, Sandstone, Tuff, Gabbro and Diorite. Some engineering geological characteristics based on which units of studied tunnels had been discriminated in this paper were lithology of strata, diversity of structural features, and geotechnical features. 20 engineering geological sections were generally identified when the repeated units had been contemplated in various parts of the tunnel route. Engineering geology units included in Table 3 are specified with a variety of signs composed of the initial letters of 
Lithology from that set. Table 3 indicates the geological and geo mechanical properties of rock mass types. Every type of rock mass found in the tunnel was in fair rock mass condition $(25<\mathrm{GSI}<75)$. Geology longitudinal profile of Karaj-Tehran Water Conveyance Tunnel was shown can be seen in Fig. 10.

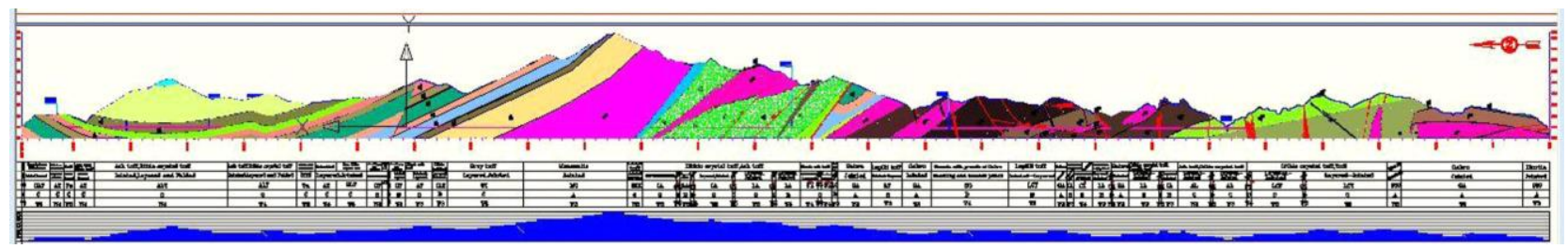

Fig. 10 Geology longitudinal profile of Karaj-Tehran water conveyance tunnel [28]

Table 3 Geomechanical attributes of engineering geological sections of tunnel

\begin{tabular}{cccccc}
\hline Eng.Geo.Unit & Sign & GSIPeak & $(\mathbf{M P a}) \sigma_{c i}$ & $\sigma_{c m}$ & $(\mathbf{G P a}) E_{r m}$ \\
& & & & $(\mathbf{M P a})$ & \\
\hline Diorite & DIO & $65-75$ & $100-200$ & 61.7 & $\mathbf{1 5}$ \\
Gabbro & GA & $60-70$ & $100-200$ & 57.4 & $\mathbf{1 2 . 5}$ \\
\hline Lithic Crystal Tuff & LCT & $40-50$ & $50-100$ & 15.2 & $\mathbf{5}$ \\
Ash and Lithic Tuff & AL & $35-45$ & $50-100$ & 13.7 & $\mathbf{4}$ \\
\hline Lithic and Lapili Tuff & LL & $60-70$ & $50-100$ & 32.6 & $\mathbf{7 . 5}$ \\
Lapili Tuff & LT & $50-60$ & $50-100$ & 16.2 & $\mathbf{5}$ \\
Gabbro Rubble & BG & $55-65$ & $50-75$ & 17.1 & $\mathbf{7 . 5}$ \\
\hline Thick Lithic Tuff & LC & $50-60$ & $100-150$ & 31.2 & $\mathbf{7 . 5}$ \\
\hline Lithic and Ash Tuff & LA & $55-65$ & $50-100$ & 20.8 & $\mathbf{7 . 5}$ \\
\hline
\end{tabular}




\begin{tabular}{cccccc}
\hline Massive Lipili Tuff & MLT & $50-60$ & $50-100$ & 26.3 & $\mathbf{5}$ \\
Monzonite & MO & $70-80$ & $100-200$ & 69.3 & $\mathbf{1 5}$ \\
Gray Tuff & GT & $50-60$ & $50-100$ & 16.6 & $\mathbf{5}$ \\
Lithic Lapili Tuff & LLT & $65-75$ & $100-150$ & 43.5 & $\mathbf{1 0}$ \\
Ash Tuff & AT & $35-45$ & $50-100$ & 8.8 & $\mathbf{2 . 5}$ \\
Cream Tuff & CT & $70-80$ & $100-150$ & 44.5 & $\mathbf{1 0}$ \\
Gray Lithic Tuff & GLT & $45-55$ & $50-100$ & 22.5 & $\mathbf{5}$ \\
Green and Cream Tuff & TU & $45-55$ & $100-150$ & 24.7 & $\mathbf{7 . 5}$ \\
Ash Lithic Tuff & ALT & $40-50$ & $50-100$ & 9.9 & $\mathbf{4}$ \\
Fractured Zone & FZ & $30-40$ & --- & 8.1 & $\mathbf{2 . 5}$ \\
Crushed Zone & CZ & $20-30$ & --- & 6.3 & $\mathbf{1 . 5}$ \\
\hline
\end{tabular}

To study in depth, the rock masses were scrutinized and then classified with respect to the geological strength index [given by Hoek and Brown (1997)]. The entire geological units were subsequently arranged in three categories of very weak rock masses (GSI $<30)$, heavily and averagely jointed rock masses (40< GSI $<70)$, and very good quality rock masses ( $70<\mathrm{GSI}<90)$. The specific energy of TBM will be determined in the following section with regard to the strain energy of rock mass for each category.

Table 4 Rock mass categorization based on GSI

\begin{tabular}{|c|c|c|}
\hline GSI & Engineering Geological units & Post Failure Behavior \\
\hline 30> GSI & FZ-CZ & Perfectly Plastic \\
\hline \multirow[t]{2}{*}{$40<$ GSI $<70$} & GA-LCT-AL-LL-LT-BG-LC-LA-MLT-GT- & Strain Softening \\
\hline & LLT-AT-GLT-TU-ALT & \\
\hline
\end{tabular}




\section{- Predicting the Specific Energy of TBM by employing the strain energy of rock mass}

As mentioned above, this section aims to utilize the strain energy of rock mass (W) to predict the specific energy of TBM (SE). To achieve this aim, an attempt was made to identify 83 sections in different parts of Karaj-Tehran water conveyance tunnel. The strain energy (W) was then calculated using respectively Eqs. 19-23 and Eqs. 14-16 to estimate the drop modulus. The least and the most of strain energy (W) were found to differ between 0.04 and 4.51, relying upon two criteria of the rock mass quality and confinement stress. So, the higher the confinement stress and the lower the quality of rock mass, the higher the strain energy (W) will be. The reverse can be also true. Two steps were taken in this stage. At the first step, to determine what kind of relationship exists between these two parameters, the regression analysis was used (see Fig. 11). As the results revealed, both parameters directly related to each other. To acquire the Specific Energy of TBM, a new logarithmic equation was then suggested. The best correspondence between both parameters is achieved when Alejano's drop modulus equations (estimated based on calculating the reduction coefficient of deformation modulus $\omega$ ) are used to estimate the strain energy of rock mass. The statistical analysis was used to procure the following equation between both parameters with $\mathrm{R}^{2}=0.668$ :

$S E=9.097 \ln (W)+45.27$ 


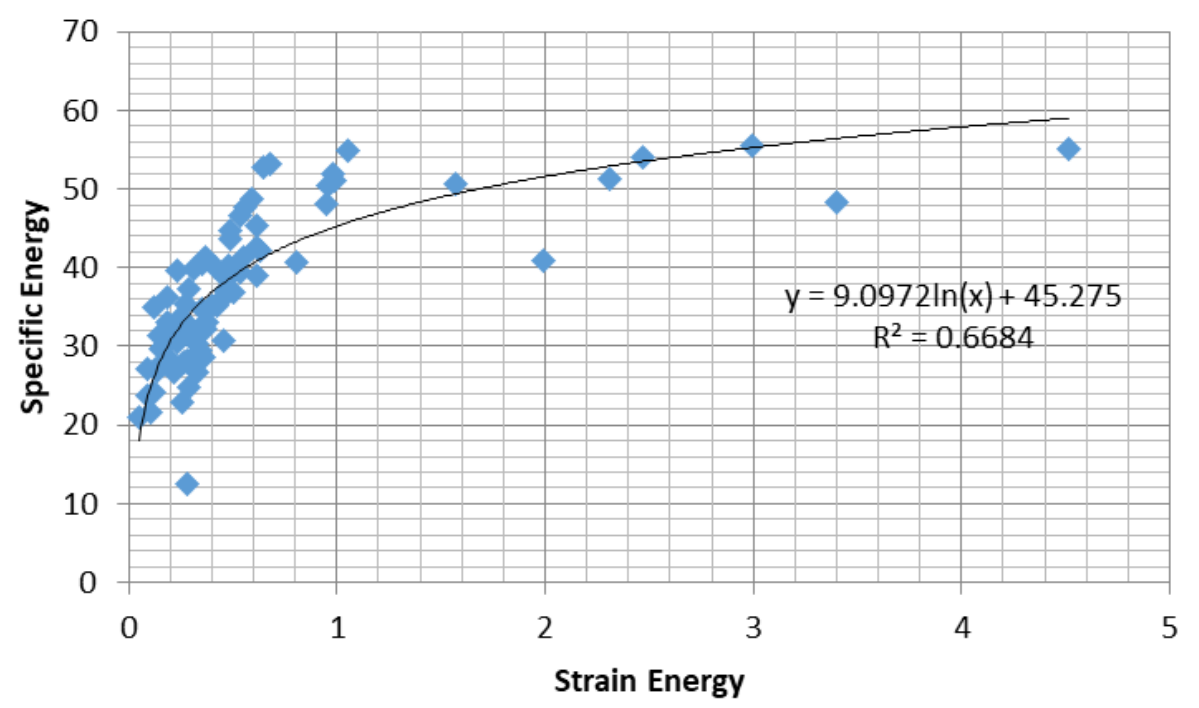

Fig. 11 Relation between Specific Energy and Strain Energy for all rock mass classes

The second step was taken to classify the rock masses based on both the geological strength index, put forward by Hoek and Brown (1997), and their post failure behavior. The achieved data was then put in three groups of rock masses with perfectly plastic $(\mathrm{GSI}<30)$, Strain Softening $(40<\mathrm{GSI}<70)$, and brittle post failure behavior (see Table 4). Each group was afterwards statistically analyzed concerning the strain energy of rock masses to have an estimation of the specific energy of TBM. 


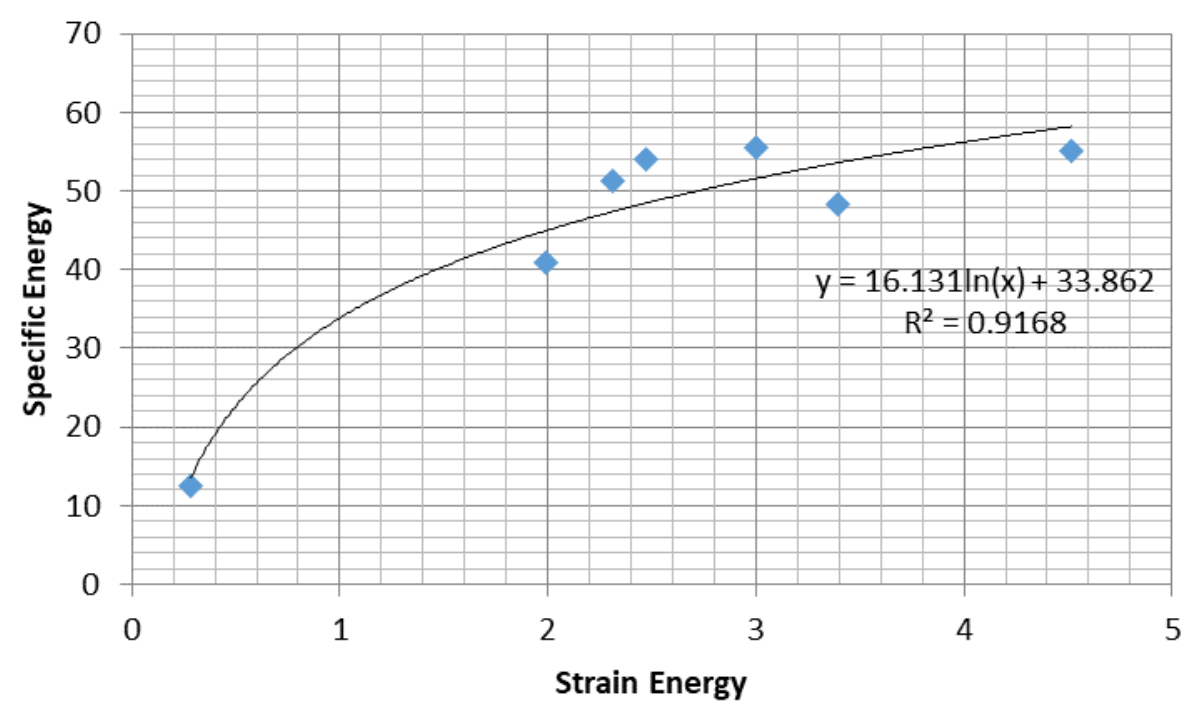

Fig. 12 Relation between the Specific Energy of TBM and the Strain Energy of rock mass in perfectly plastic post peak behavior of rock mass.

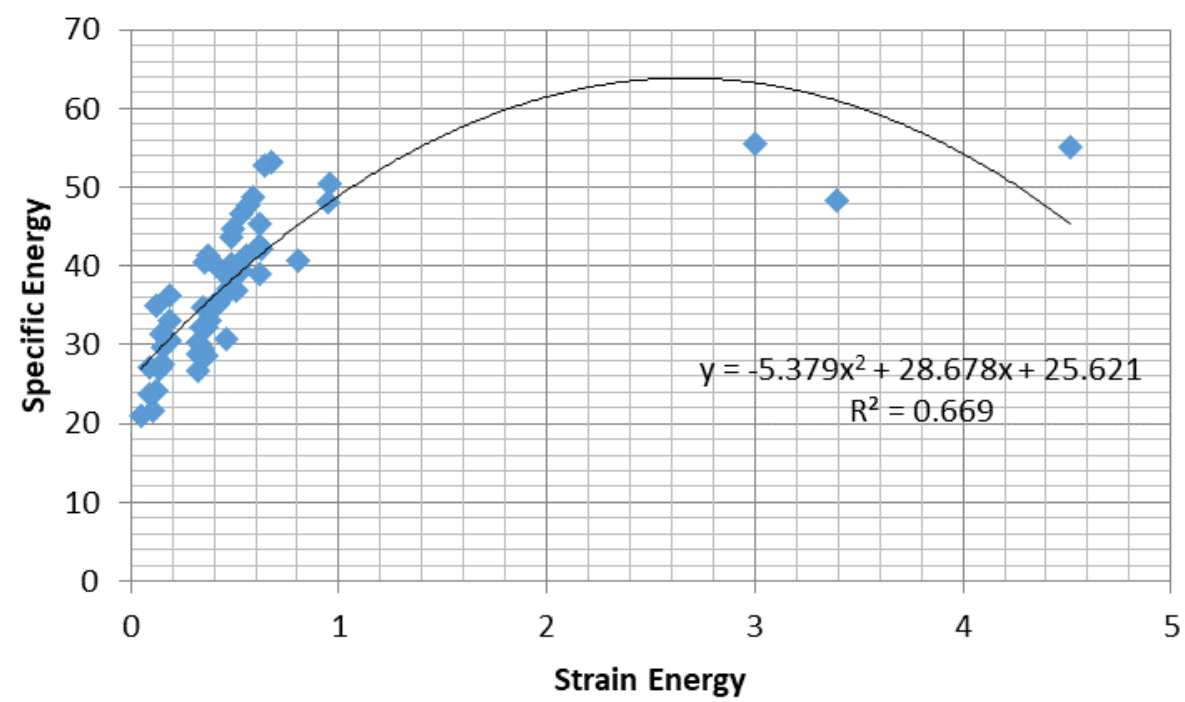

Fig. 13 Relation between the Specific Energy of TBM and the Strain Energy of rock mass strain softening post peak behavior of rock mass. 


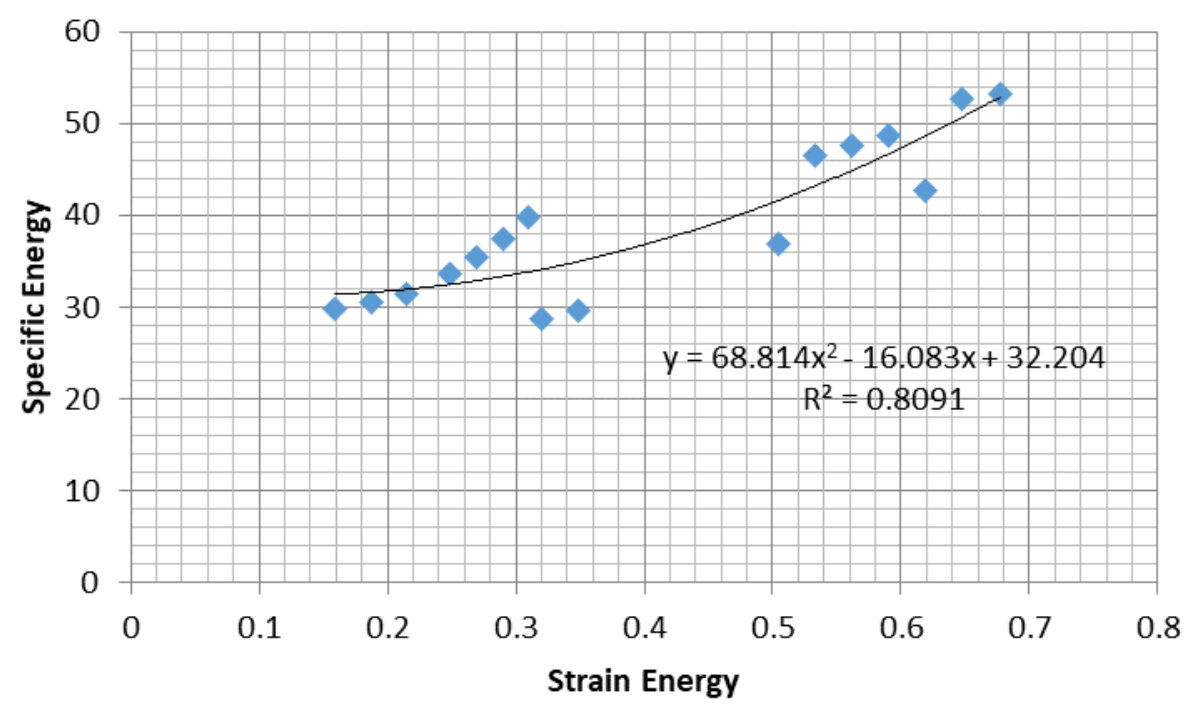

Fig. 14 Relation between the Specific Energy of TBM and the Strain Energy of rock mass brittle post peak behavior of rock mass.

The Figs. 12-14 indicate that there is a direct relationship between the specific energy of TBM and the strain energy of rock mass in each group. The succeeding equations are presented to evaluate the specific energy of TBM in each group.

$S E=16.13 \ln (W)+33.86$

(25)

$\begin{array}{lcc}S E=4.998 W^{2}+33.16 W+22.97 & \text { For } 40<\mathrm{GSI}<70 & \mathrm{R}^{2}=0.712 \\ S E=68.81 W^{2}-16.08 W+32.20 & \text { For } 70<\mathrm{GSI}<90 & \mathrm{R}^{2}=0.809\end{array}$

Where SE stands for the Specific Energy of TBM $\left(\frac{M I}{\mathrm{~m}^{3}}\right)$, and the W stands for the Strain Energy of rock mass $\left(\frac{M I}{\mathrm{~m}^{3}}\right)$.

\section{- Conclusion}


In view of the fact that fragile and completely plastic models are two distinctive instances of strain-softening behavior, it was applied to model the rock masses in this study. Moreover, it has the capacity to demonstrate the results in macroscopic form which is practically perceivable. It was found that when the quality of rock mass and the minimum principal stress respectively ascended and descended, the consumed amount of rock mass strain energy and TBM specific energy would descend. This occurs in that rock mass was observed to alter their plasticity behavior from elastic plastic to elastic brittle and the drop modulus led to infinite value as well. The reverse can also be true. The statistical analysis reveals that by applying Eqs. 9-11 to assess the drop modulus, the obtained correlation between both parameters was at its highest level. Ultimately, an estimation was done to determine the kind of relationship between the strain energy of rock mass and the specific energy of TBM, in Karaj-Tehran water conveyance tunnel of Iran and a logarithmic equation was subsequently offered to evaluate the specific energy of TBM. The amplitude of SE was found to be high. To have a stronger correlation between the above parameters, the data was classified, on the basis of the geological strength index and in respect to the post failure behavior of rock mass, into three categories of perfectly plastic (GSI<30), strain softening $(40<\mathrm{GSI}<70)$ and brittle $(70<\mathrm{GSI}<90)$. The rock mass strain energy in each category was also exerted to assess the TBM specific energy in a statistical analysis. The findings demonstrated firstly that two mentioned parameters were in a direct relationship with each other and that by employing the logarithmic and nonlinear equations to assess the TMB specific energy, the strongest correlation could be acquired. Lastly, the existed correlation between both parameters is accentuated to be raised in regard to the classification of the rock masses based on their post peak behavior [suggested by Hoek and Brown (1997)]. 


\section{References}

[1] Ramezanzadeh, A., J. Rostami, and R. Kastner. Performance Prediction Models for Hard Rock Tunnel Boring Machines. in Proceedings of Sixth Iranian Tunneling Conference, Tehran, Iran. 2004.

[2] Acaroglu, O., L. Ozdemir, and B. Asbury, A fuzzy logic model to predict specific energy requirement for TBM performance prediction. Tunnelling and Underground Space Technology, 2008. 23(5): p. 600-608.

[3] Altindag, R., Correlation of specific energy with rock brittleness concepts on rock cutting. Journal of the South African Institute of Mining and Metallurgy, 2003. 103(3): p. 163171.

[4] Teale, R. The concept of specific energy in rock drilling. in International Journal of Rock Mechanics and Mining Sciences \& Geomechanics Abstracts. 1965. Elsevier.

[5] Zhang, Q., et al. Modeling Specific Energy for Shield Machine by Non-linear Multiple Regression Method and Mechanical Analysis. in Proceedings of the 2011 2nd International Congress on Computer Applications and Computational Science. 2012. Springer.

[6] Wang, L., et al., The energy method to predict disc cutter wear extent for hard rock TBMs. Tunnelling and Underground Space Technology, 2012. 28: p. 183-191.

[7] Bilgin, N., H. Copur, and C. Balci, Mechanical Excavation in Mining and Civil Industries. 2013: CRC Press.

[8] Roxborough, F.F. and H.R. Phillips. Rock excavation by disc cutter. in International Journal of Rock Mechanics and Mining Sciences \& Geomechanics Abstracts. 1975. Elsevier.

[9] Thuro, K. Prediction of drillability in hard rock tunnelling by drilling and blasting. in World Tunnel Congress. 1997.

[10 Atici, U. and A. Ersoy, Correlation of specific energy of cutting saws and drilling bits with rock brittleness and destruction energy. Journal of Materials Processing Technology, 2009. 209(5): p. 2602-2612.

[11] Dehkordi, M.S., et al., Application of the strain energy to estimate the rock load in nonsqueezing ground condition. Archives of Mining Sciences, 2011. 56: p. 551-566.

[12] Hoek, E. and E. Brown, Practical estimates of rock mass strength. International Journal of Rock Mechanics and Mining Sciences, 1997. 34(8): p. 1165-1186.

[13] Alejano, L., et al., Application of the convergence-confinement method to tunnels in rock masses exhibiting Hoek-Brown strain-softening behaviour. International Journal of Rock Mechanics and Mining Sciences, 2010. 47(1): p. 150-160.

[14] Alejano, L., et al., Ground reaction curves for tunnels excavated in different quality rock masses showing several types of post-failure behaviour. Tunnelling and Underground Space Technology, 2009. 24(6): p. 689-705.

[15] Dehkordi, M.S., et al., Estimation of the Rock Load in Non-squeezing Ground Condition Using the Post Failure Properties of Rock Mass. Geotechnical and Geological Engineering, 2015: p. 1-14. 
[16] Dehkordi, M.S., et al., Application of the strain energy to estimate the rock load in squeezing ground condition of Eamzade Hashem tunnel in Iran. Arabian Journal of Geosciences, 2013. 6(4): p. 1241-1248.

[17] Marinos, P. and E. Hoek. GSI: a geologically friendly tool for rock mass strength estimation. in ISRM International Symposium. 2000. International Society for Rock Mechanics.

[18] Hoek, E., C. Carranza-Torres, and B. Corkum, Hoek-Brown failure criterion-2002 edition. Proceedings of NARMS-Tac, 2002: p. 267-273.

[19] Cai, M., et al., Estimation of rock mass deformation modulus and strength of jointed hard rock masses using the GSI system. International Journal of Rock Mechanics and Mining Sciences, 2004. 41(1): p. 3-19.

[20] RocScience, R., Rocscience Inc. Toronto, Canada, 2002.

[21] Hoek, E., et al. The 2008 Kersten Lecture Integration of geotechnical and structural design in tunneling. in 56th Annual Geotechnical Engineering Conference. 2008.

[22] Rummel, F. and C. Fairhurst, Determination of the post-failure behavior of brittle rock using a servo-controlled testing machine. Rock mechanics, 1970. 2(4): p. 189-204.

[23] Carranza-Torres, C. and C. Fairhurst, Application of the convergence-confinement method of tunnel design to rock masses that satisfy the Hoek-Brown failure criterion. Tunnelling and Underground Space Technology, 2000. 15(2): p. 187-213.

[24] Egger, P., Design and construction aspects of deep tunnels (with particular emphasis on strain softening rocks). Tunnelling and Underground Space Technology, 2000. 15(4): p. 403-408.

[25] Hoek, E. and M.S. Diederichs, Empirical estimation of rock mass modulus. International Journal of Rock Mechanics and Mining Sciences, 2006. 43(2): p. 203-215.

[26] Sakurai, S., Lessons learned from field measurements in tunnelling. Tunnelling and underground space technology, 1997. 12(4): p. 453-460.

[27] Sakurai, S. and K. Takeuchi, Back analysis of measured displacements of tunnels. Rock mechanics and rock engineering, 1983. 16(3): p. 173-180.

[28] Dehkordi, M.S., H. Lazemi, and K. Shahriar, Application of the strain energy ratio and the equivalent thrust per cutter to predict the penetration rate of TBM, case study: KarajTehran water conveyance tunnel of Iran. Arabian Journal of Geosciences, 2014: p. 1-10. 
Figures

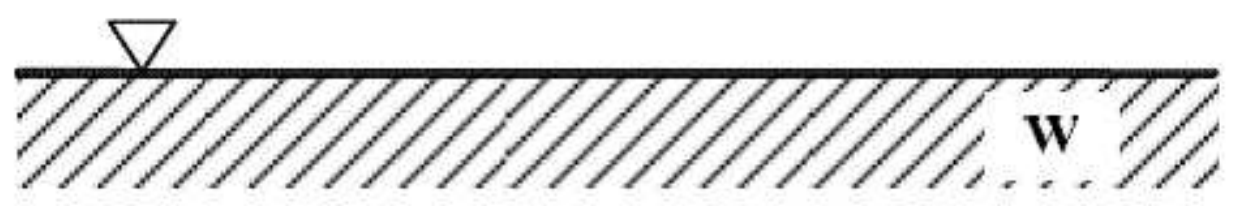

Advance Direction

$$
\mathrm{E}_{\mathrm{s}}=\mathrm{E}_{\mathrm{F}}+\mathrm{E}_{\mathrm{T}}
$$

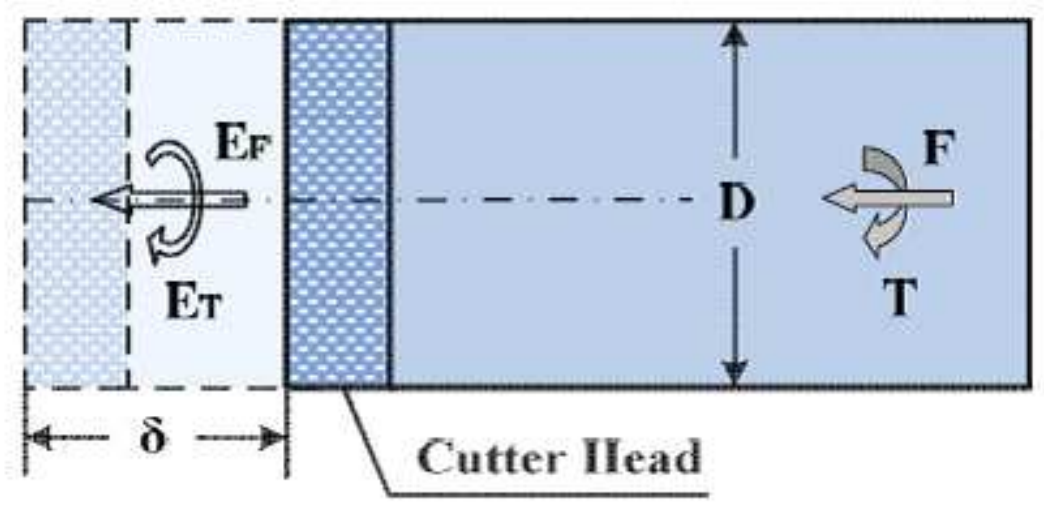

Figure 1

Schematic representation for the working process of a shield machine [5]
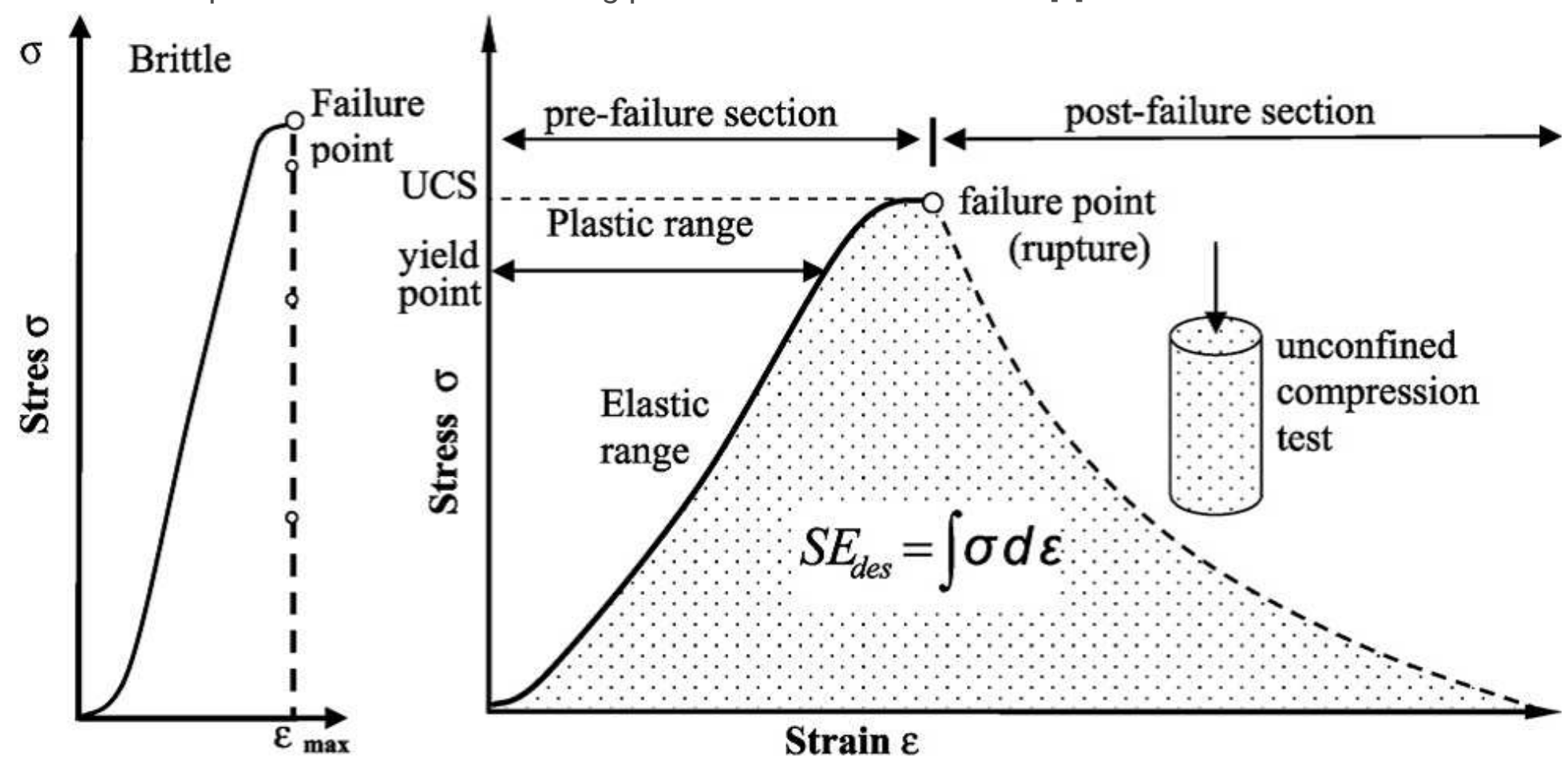

Figure 2 
Assessing the destruction specific energy (SEdes) out of the stress-strain curve of a rock sample subjected to unconfined compression test [10].

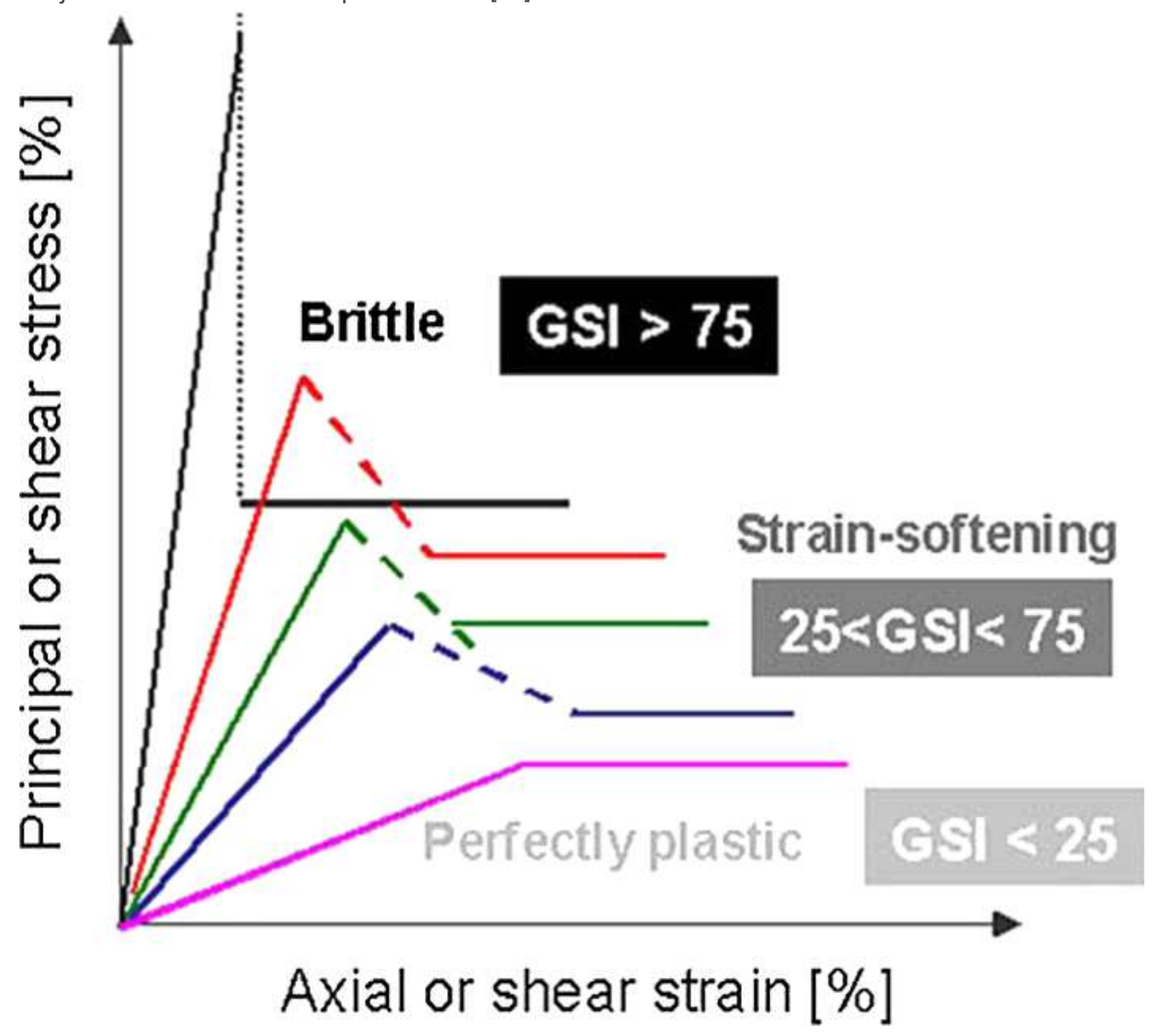

Figure 3

Various post-failure behavior styles shown by assorted rock masses having different geological strength indices (GSI) [13] 


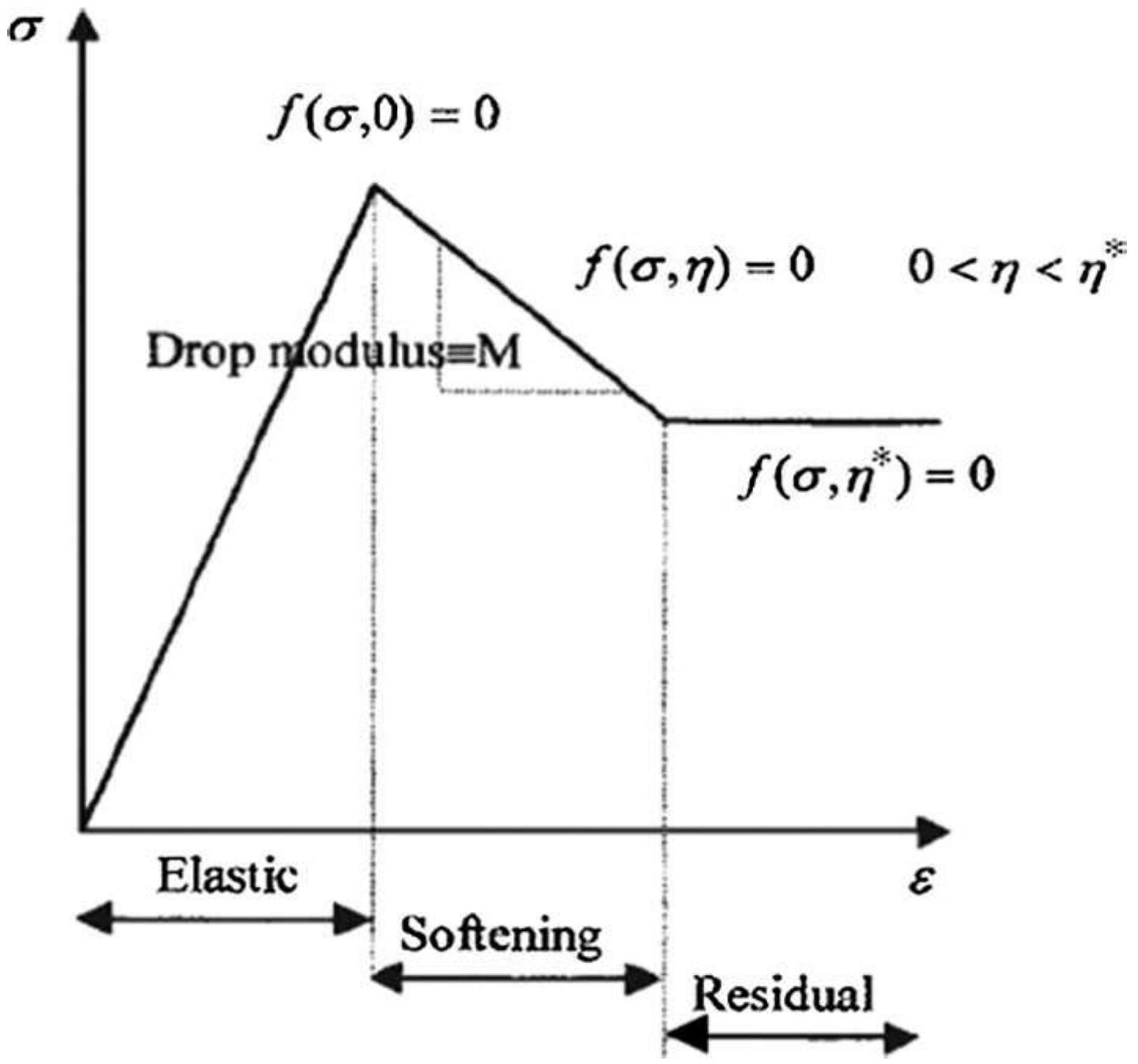

Figure 4

Stress-strain curve with regard to an unconfined test performed on a specimen of strain-softening material [13] 
(a)

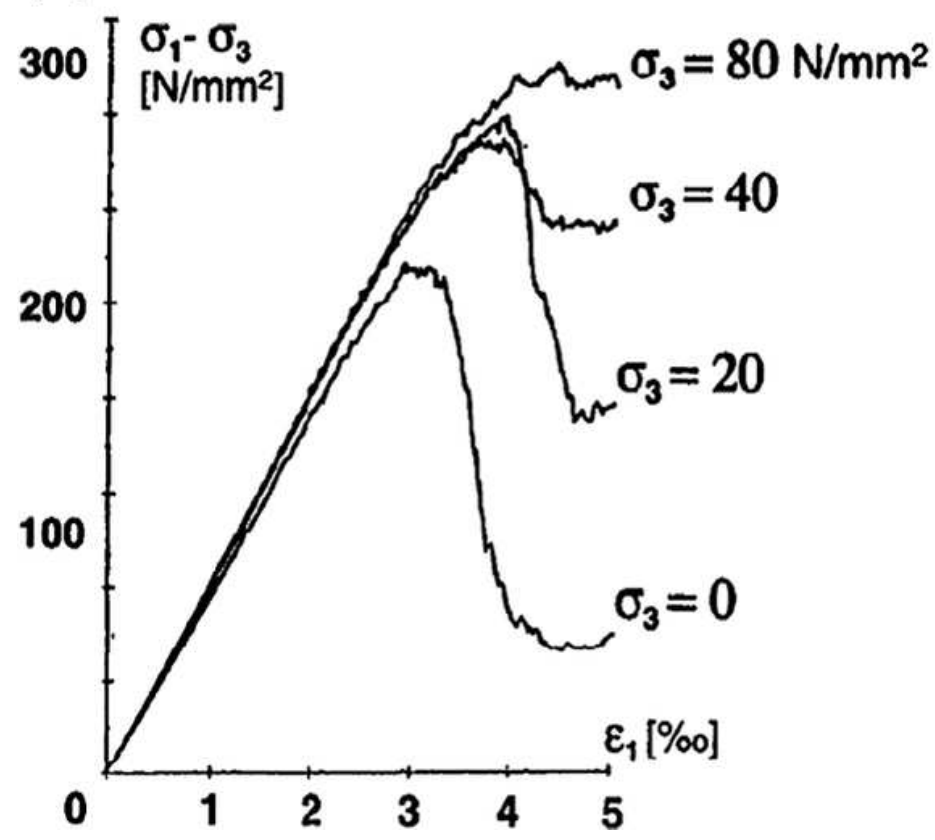

(b)

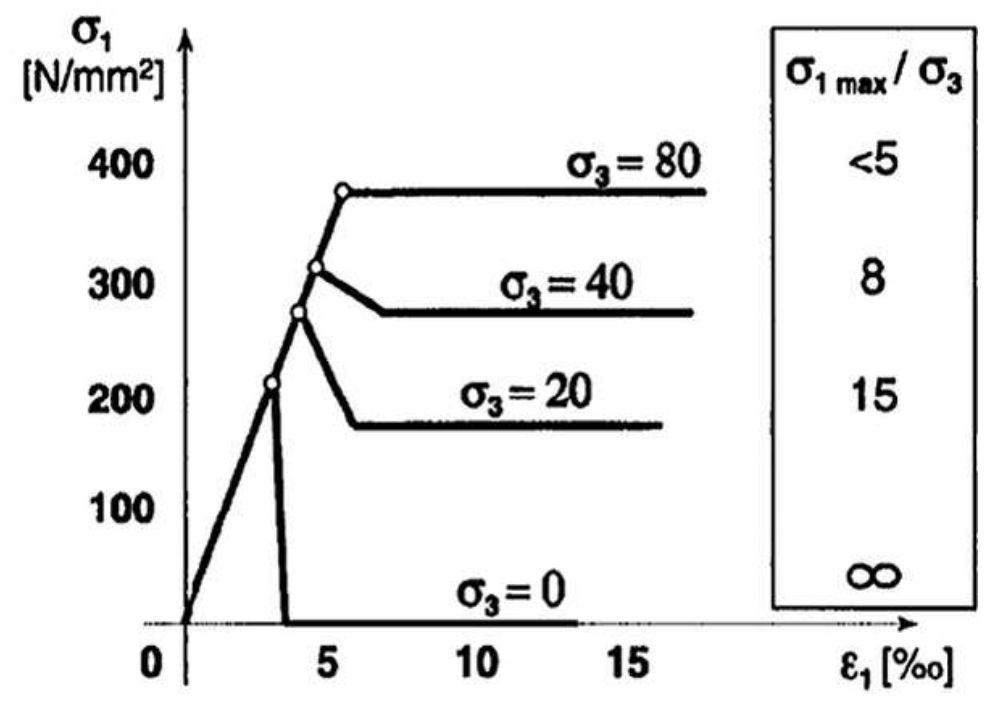

Figure 5

The post-failure behavior of granite samples determined by the confinement pressure. (a) Outcomes of a numerical simulation of the 3-axial tests.(b) Schematic behavior [24]. 


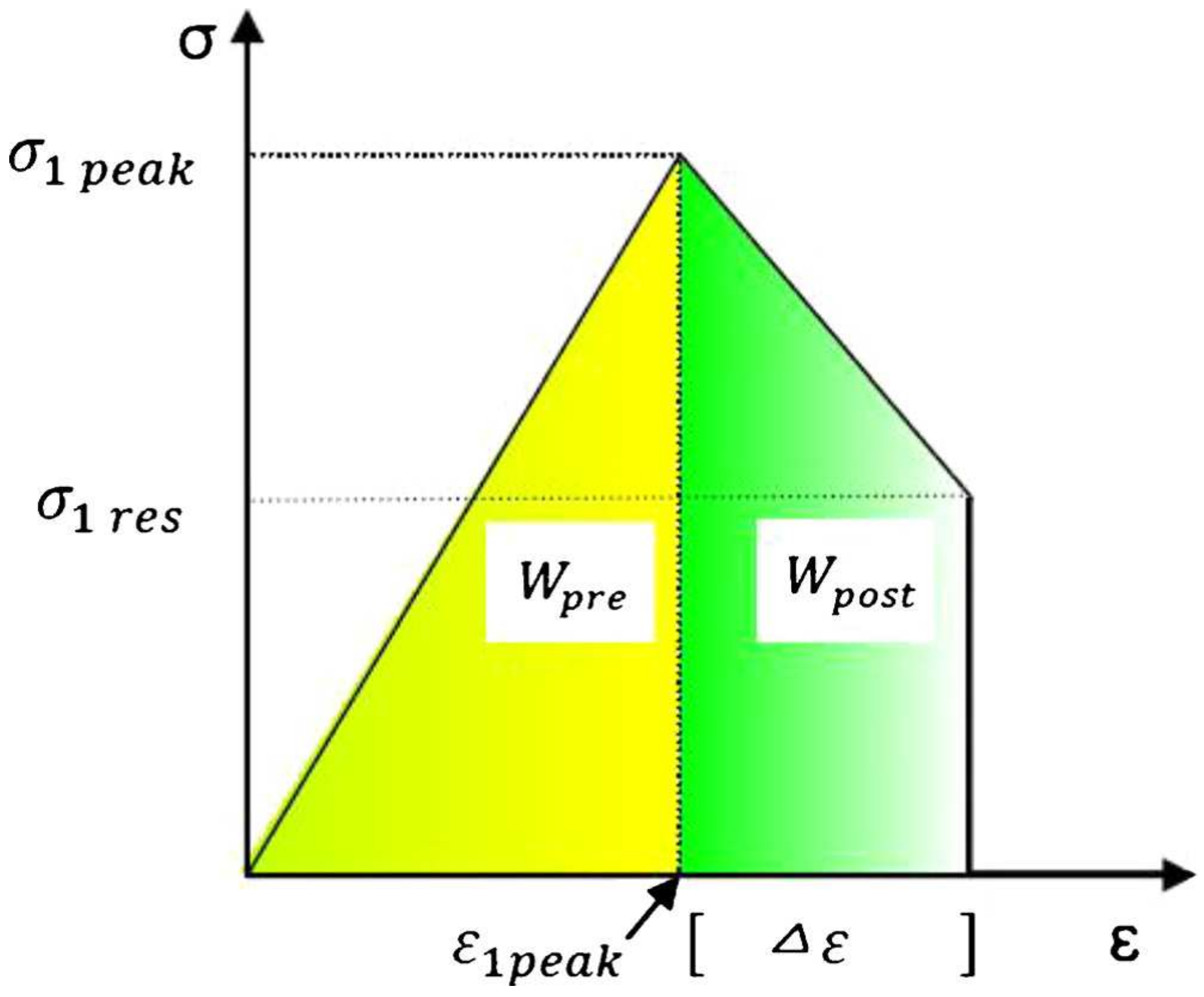

Figure 6

Supplied and unconsumed strain energy in pre- and post-failure, respectively [28] 


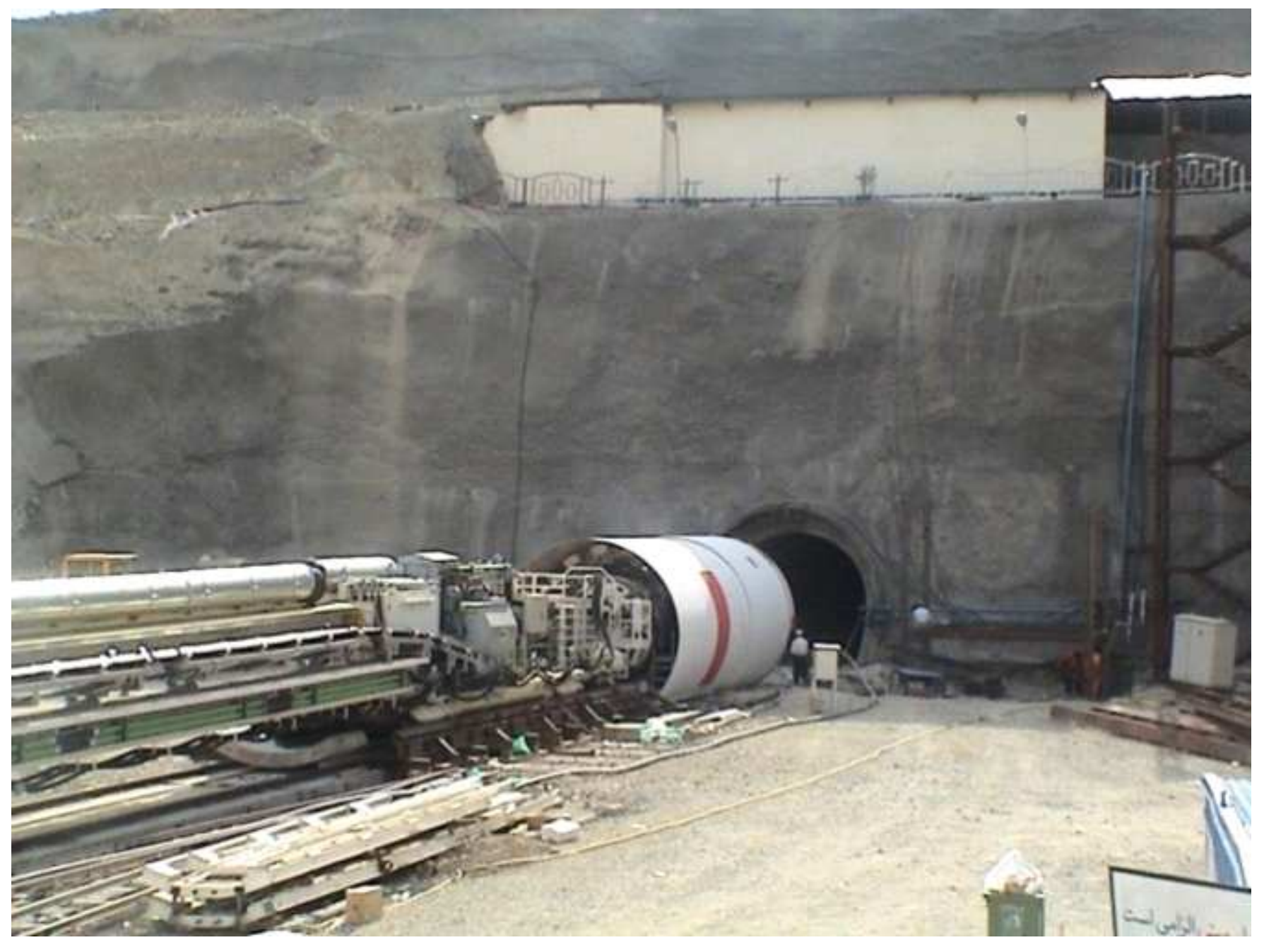

\section{Figure 7}

The portal of Karaj-Tehran water conveyance tunnel

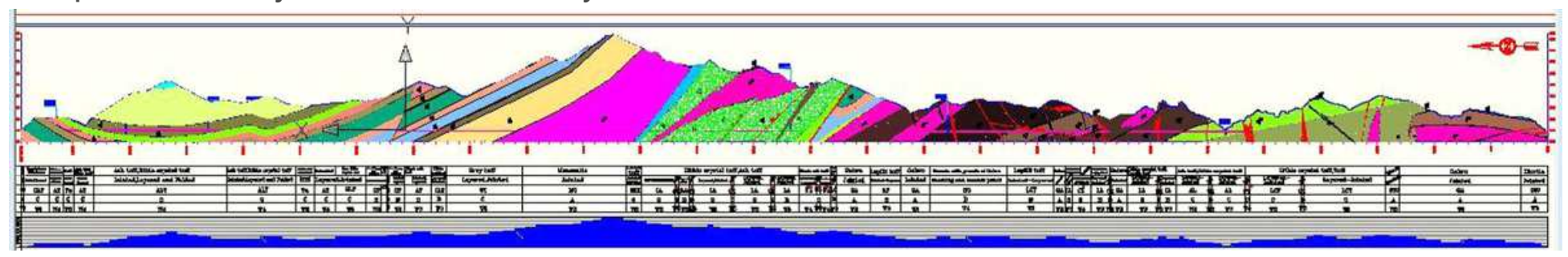

Figure 8

Geology longitudinal profile of Karaj-Tehran water conveyance tunnel [28] 


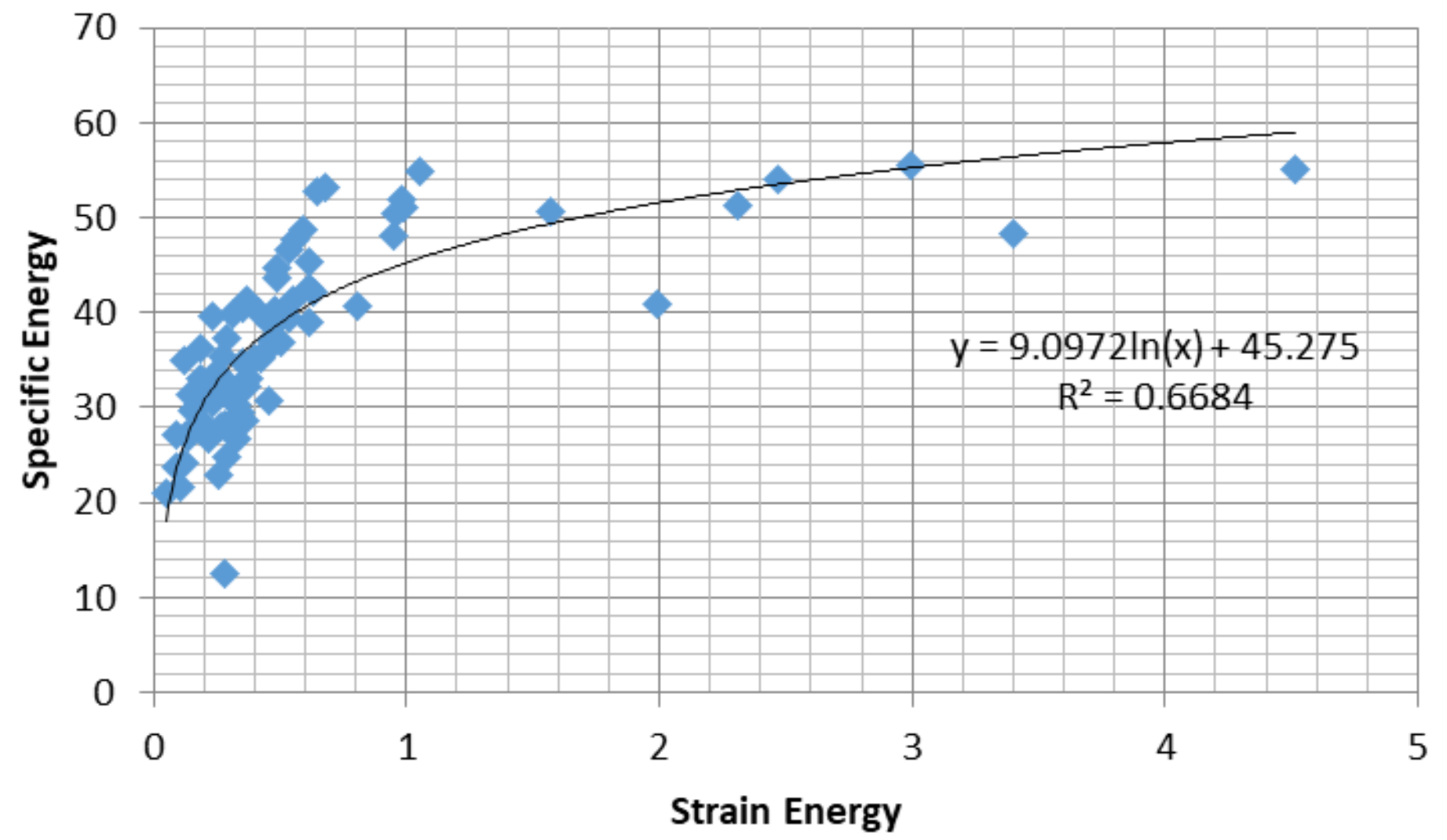

Figure 9

Relation between Specific Energy and Strain Energy for all rock mass classes 


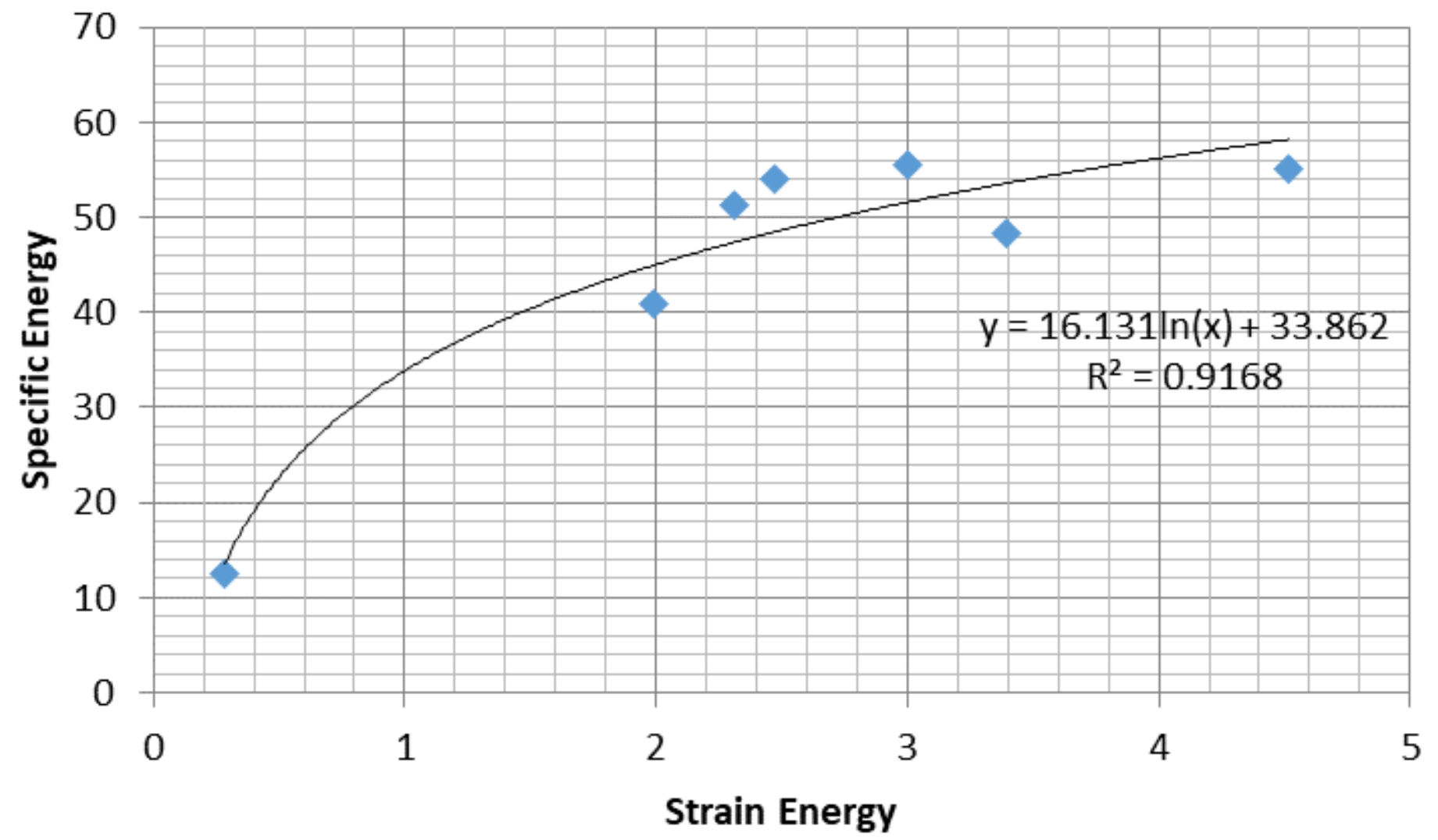

Figure 10

Relation between the Specific Energy of TBM and the Strain Energy of rock mass in perfectly plastic post peak behavior of rock mass. 


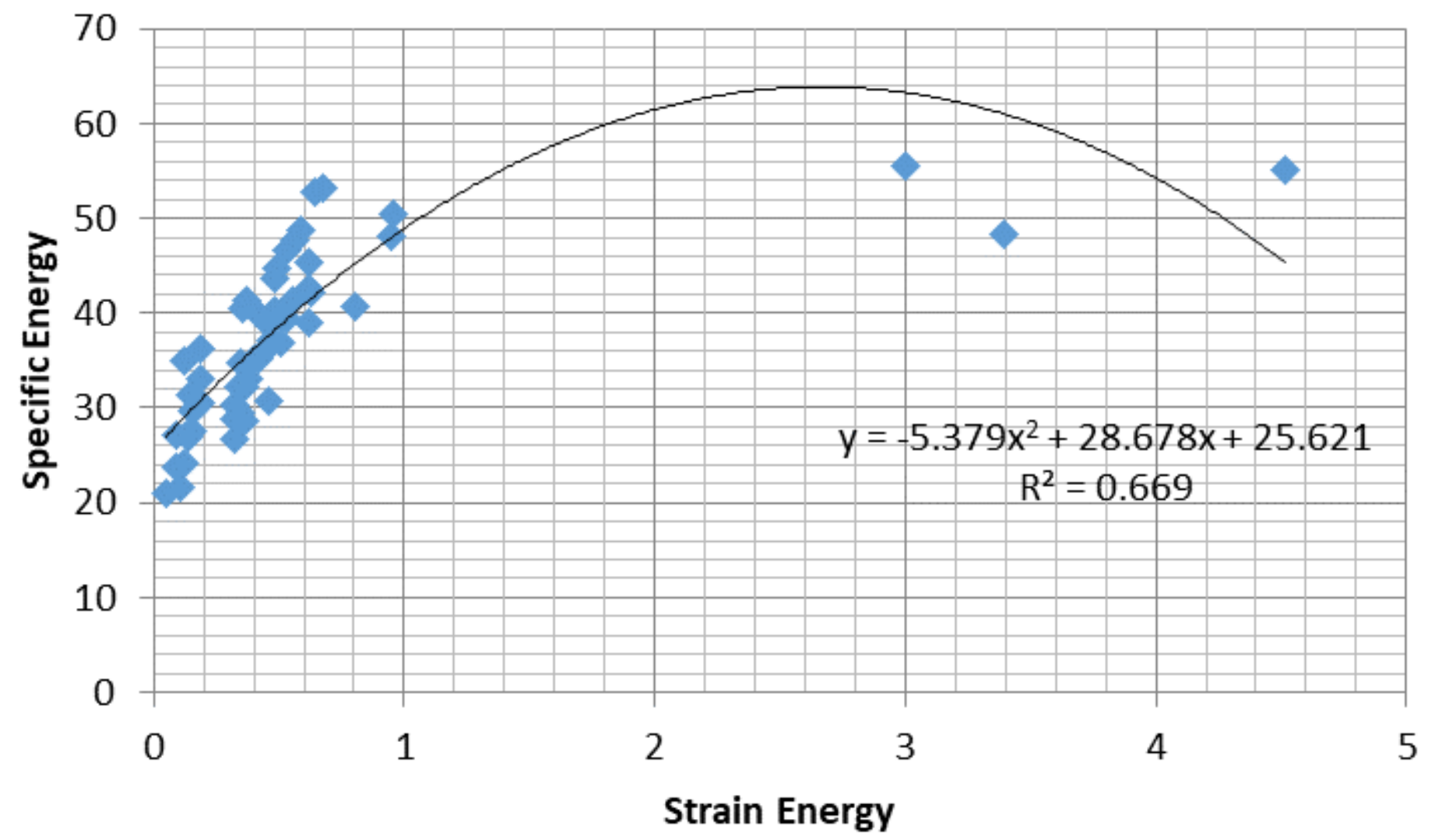

Figure 11

Relation between the Specific Energy of TBM and the Strain Energy of rock mass strain softening post peak behavior of rock mass. 


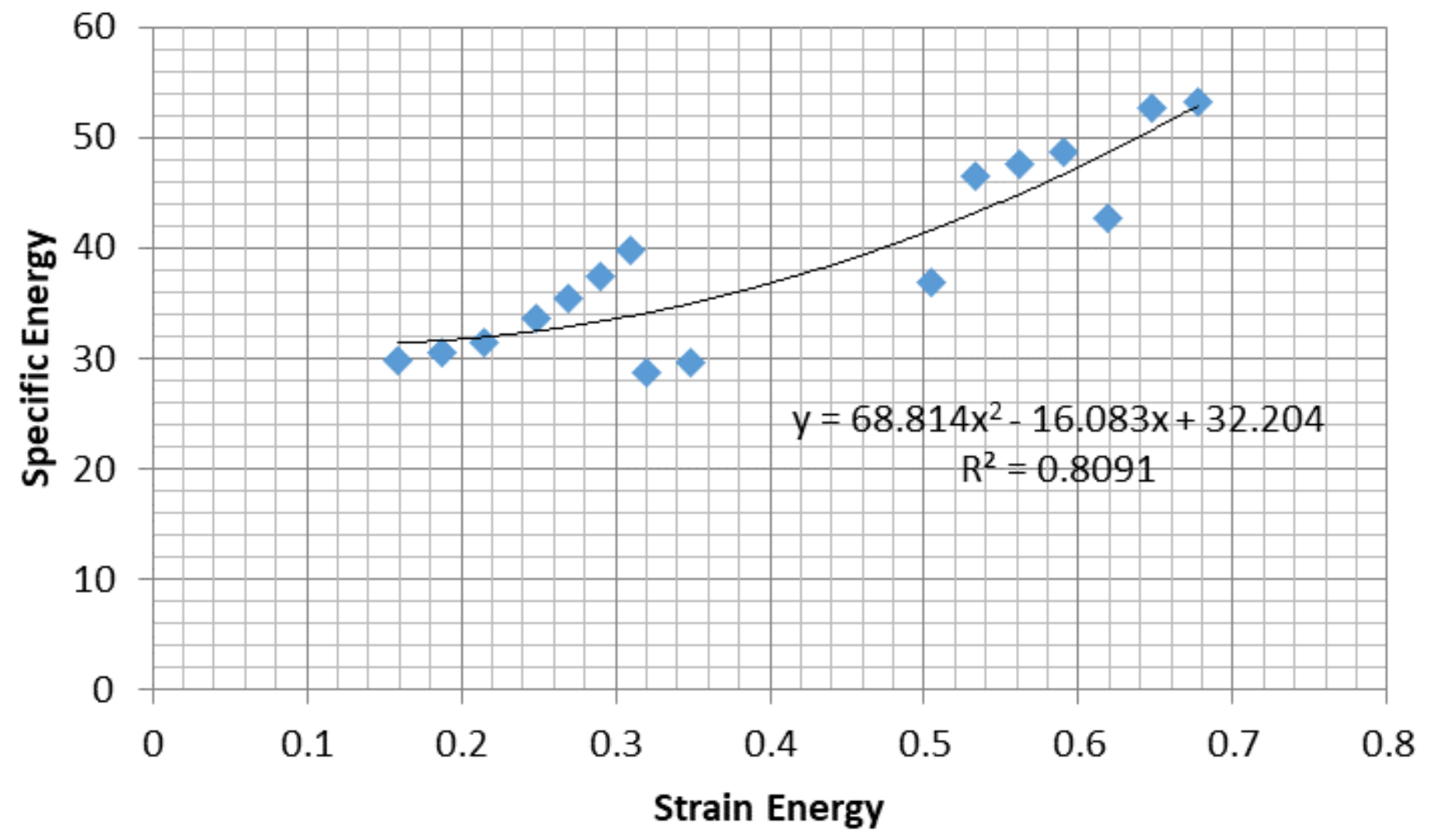

Figure 12

Relation between the Specific Energy of TBM and the Strain Energy of rock mass brittle post peak behavior of rock mass. 